\title{
Implications of seasonal mixing for phytoplankton production and bloom development
}

\author{
F. Peeters · O. Kerimoglu - D. Straile
}

\begin{abstract}
Based on a 1D model considering phytoplankton and nutrients in a vertical water column, we investigate the consequences of temporal and spatial variations in turbulent mixing for phytoplankton production and biomass. We show that in seasonally mixed systems, the processes controlling phytoplankton production and the sensitivity of phytoplankton abundance to ambient light, trophic state and mixed-layer depth differ substantially from those at steady state in systems with time-constant diffusivities. In seasonally mixed systems, the annually replenished nutrient pool in the euphotic zone is an important factor for phytoplankton production supporting bloom development, whereas without winter mixing, production mainly depends on the diffusive nutrient flux during stratified conditions. Seasonal changes in water column production are predominantly determined by seasonal changes in phytoplankton abundance, but also by seasonal changes in specific production resulting from the transport of nutrients, the exploitation of the nutrient pool and the increase in light shading associated with phytoplankton growth. The interplay between seasonal mixing and the vertical distribution of mixing intensities is a key factor determining the relative importance of the processes controlling phytoplankton production and the sensitivity of the size and timing of the annual maximum phytoplankton abundance to the abiotic conditions.
\end{abstract}

F. Peeters $(\Omega) \cdot$ O. Kerimoglu $\cdot$ D. Straile Limnological Institute, University of Konstanz, Mainaustrasse 252,

78464 Konstanz, Germany

e-mail: frank.peeters@uni-konstanz.de
Keywords Phytoplankton - Mixing - Light - Nutrients . Phenology $\cdot$ Seasonal mixing $\cdot$ Algal bloom

\section{Introduction}

Light energy and mineral nutrients are important factors determining primary production in aquatic systems. In the pelagic zone, both resources, light energy and nutrients, exhibit strong vertical gradients in the water column. Seasonal changes in the intensity and distribution of vertical turbulent mixing causes pronounced seasonal variations in the availability of these resources to primary producers. The vertical structuring of the water column and its seasonal variation caused by seasonal changes in mixing are key characteristics of pelagic habitats that have led to the classical distinction between epilimnion, metalimnion and hypolimnion as zones where similar ecological processes occur and the classification of lakes according to their mixing regimes, e.g., monomictic, dimictic or polimictic lakes, indicating similarities in typical seasonal behaviour of lake ecosystems (Hutchinson 1957). Seasonal and vertical variation in mixing intensity have a major affect on the vertical distribution of primary producers relative to their light energy resource and on the vertical distribution of the nutrient concentrations. Therefore, the seasonal change in mixing intensity is an important factor for water column production and spring phytoplankton bloom development in the ocean (e.g. Falkowski 1994; Sharples et al. 2006) and in lakes (e.g. Sommer et al. 1986; Peeters et al. 2007a).

The onset of spring phytoplankton growth sets the beginning of seasonal plankton succession, one of the most prominent features and intensively studied topics in lake ecology (Sommer et al. 1986). The annual spring maximum in phytoplankton concentrations is a key event in plankton 
succession whose timing and magnitude is important for food web interactions and biogeochemical processes. For example, the timing of phytoplankton blooms is important for the interaction between phytoplankton and herbivores (Edwards and Richardson 2004; Winder and Schindler 2004). In some cases, even the life cycle of herbivores may be especially adapted to exploit the annual phytoplankton bloom (Seebens et al. 2009). Phytoplankton blooms can have a significant effect on biogeochemical fluxes by influencing sedimentation rates due to density-dependent coagu lation (Kiorboe et al. 1994). Furthermore, blooms of harmful algae can influence overall ecosystem integrity as well as human health and industries (Landsberg 2002).

In numerous studies, the role of mixing intensity, mixing depth, sedimentation and light limitation for phytoplankton production has been investigated assuming time-constant mixing intensities (e.g. Huisman et al. 1999, 2002; Diehl 2002; Diehl et al. 2002; Huisman and Sommeijer 2002; O'Brien et al. 2003). These studies illustrated, e.g. that mixing, counteracting sedimentation in shallow systems and transporting phytoplankton to depths below the euphotic zone in deep systems, affects the persistence range of phytoplankton. Survival of sinking phytoplankton populations is only possible in water columns between a minimum and maximum water depth and a minimum and maximum level of mixing intensity. The values of critical depths and critical mixing intensities depend on the parameters of specific productivity and sinking rate (e.g. Huisman et al. 1999, 2002).

Nutrient limitation, a key factor restricting phytoplankton production during seasonal succession in many lakes, alters the conclusions on the role of mixing for primary production inferred from the simplified models considering only light limitation (e.g. Yoshiyama and Nakajima 2002; Huisman et al. 2006; Ryabov et al. 2010; Jäger et al. 2010; Mellard et al. 2011). When including nutrients, mixing does not only affect the transport of phytoplankton relative to its resource as in the case of light energy but additionally affects the distribution of the resource itself. Jäger et al. (2010) concluded that persistence boundaries with respect to water column depth and mixing intensity of a nutrient- and light-limited phytoplankton population are determined by sinking losses and light limitation, whereas nutrients are the most limiting factor for total biomass.

These previous studies considering light- and nutrientlimited phytoplankton in vertically resolved systems focused on long-term solutions of models assuming timeconstant diffusivities and did not include seasonal variation in mixing conditions. However, as pointed out by Hastings (2004): "with seasonality, long-term solutions can be essentially irrelevant" which might be important especially for plankton communities where "steady state is the exception rather than the rule" (Sommer 1985).

In many lakes and in major parts of the oceans (with the exception of advection-dominated regions in the coastal ocean and systems in tropical regions or with a permanent ice cover), seasonal mixing results in a seasonal increase in downward transport of phytoplankton leading to increased water column light limitation and consequently to a substantial reduction in phytoplankton abundance, but also results in a seasonal replenishment of nutrients in the euphotic zone, thus providing the resource for seasonal phytoplankton growth. Hence, seasonal changes in vertical mixing cause seasonal changes in water column production and therefore support phytoplankton bloom development. This suggests that the understanding of phytoplankton abundances during the season requires consideration of seasonal changes in the spatial distribution and intensity of vertical mixing.

One possibility for investigating the non-equilibrium conditions arising in seasonally forced systems is to consider transient dynamics in theoretical modelling studies. For example Huppert et al. $(2002,2005)$ investigated transient dynamics in minimal one-box models and concluded that phytoplankton blooms can develop if nutrient levels exceed a threshold value and develop recurrently if phytoplankton production changes seasonally. Jäger et al. (2008) studied the effects of nutrient availability and mixing depths on plankton bloom magnitudes and phenology by analysing the transient dynamics of a phytoplankton-herbivore model, but without considering spatio-temporal patterns in mixing or resolving the vertical dimension. The transient dynamics approach however relies critically on the assumption that the model results are insensitive to the prescribed initial conditions.

Here, we employ a vertically resolved phytoplankton model and simulate seasonal phytoplankton dynamics over several years. The analysis is focussed on the consequences of seasonal changes in vertical mixing. Seasonal changes in solar radiation are not addressed (for the latter, see Litchman and Klausmeier 2001). First, we investigate the consequences of seasonal mixing for phytoplankton production and abundances in a $50-\mathrm{m}$ deep water column. Based on numerical experiments, we demonstrate that the seasonal variation and the vertical heterogeneity in mixing intensity significantly affect timing and height of the seasonal maximum in phytoplankton production and phytoplankton biomass. Furthermore, we illustrate that the sensitivity of phytoplankton biomass to external forcing factors (light intensity at the lake surface, nutrient loading) and the control of phytoplankton during the season is different in seasonally mixed systems than at steady state conditions arising in models assuming time-constant diffusivities. Finally, we demonstrate that the abundance and persistence of phytoplankton in water columns of different depths depends on the combination of seasonality and vertical variation in mixing conditions. 


\section{Methods}

The model and analysis of model results

The model applied in this study corresponds to the model by Jäger et al. (2010). Concentrations of phytoplankton carbon biomass $(A)$, particulate nutrients bound in algae $\left(R_{b}\right)$ and dissolved nutrients $\left(R_{d}\right)$ are simulated as dynamic state variables in a ID vertical water column and are linked to a sediment pool of nutrients $\left(R_{S}\right)$ that is also simulated dynamically. The model considers limitation of specific production $p_{\text {spec }}$ by light intensity $I$ that is attenuated in the water column by algae and background attenuation, limitation of $p_{\text {spec }}$ by nutrients using a cell quota model with cell quota $q$ and nutrient uptake rate $\rho$, losses of algae by respiration with rate $l_{\mathrm{hg}}$, transport of algae and nutrients by turbulent mixing expressed as a turbulent diffusivity $d$, sedimentation of algae and particulate nutrients using a sinking velocity $v$ and return of dissolved nutrients from re-mineralization of particulate nutrients at rate $r$ in the sediment pool to the bottom of the water column (see Jäger et al. 2010):

$$
\begin{aligned}
& \frac{\partial A}{\partial t}=P_{\mathrm{spec}}(I, q) \cdot A \quad-l_{\mathrm{bg}} \cdot A \quad-v \cdot \frac{\partial A}{\partial z}+\frac{\partial}{\partial z}\left(d \cdot \frac{\partial A}{\partial z}\right) \\
& \frac{\partial R_{b}}{\partial t}=\rho\left(q, R_{d}\right) \cdot A-l_{\mathrm{bg}} \cdot R_{b}-v \cdot \frac{\partial R_{b}}{\partial z}+\frac{\partial}{\partial z}\left(d \cdot \frac{\partial R_{b}}{\partial z}\right) \\
& \frac{\partial R_{d}}{\partial t}=-\rho\left(q, R_{d}\right) \cdot A+l_{\mathrm{bg}} \cdot R_{b} \quad+\frac{\partial}{\partial z}\left(d \cdot \frac{\partial R_{d}}{\partial z}\right) \\
& \frac{\partial R_{s}}{\partial t}=v \cdot R_{b}\left(z_{\max }\right)-r \cdot R_{s} \\
& P_{\text {spec }}(I, q)=\mu_{\max }\left(1-\frac{q_{\min }}{q}\right) \frac{I(z)}{h+I(z)} \\
& I(z)=I_{0} \exp \left(-\int_{0}^{z}\left(k \cdot A+k_{\mathrm{bg}}\right) \mathrm{d} z\right) q=\frac{R_{b}}{A} \\
& \rho\left(q, R_{d}\right)=\rho_{\max }\left(1-\frac{q-q_{\min }}{q_{\max }-q_{\min }}\right) \frac{R_{d}}{m+R_{d}}
\end{aligned}
$$

Thereby, $t$ represents time, $z$ is depth below the water surface and $z_{\max }$ is $z$ at maximum water column depth, $\mu_{\max }$ is the maximum specific algal production rate, $q_{\min }$ and $q_{\max }$ the minimum and maximum algal nutrient quota, respectively, $h$ the half-saturation constant of light-dependent algal production, $k$ the specific lightattenuation coefficient of algal biomass, $k_{\mathrm{bg}}$ the background light attenuation coefficient and $m$ the halfsaturation constant of algal nutrient uptake. Light limitation
$L_{\text {limit }}$ and nutrient limitation $N_{\text {limit }}$ are described as:

$$
\begin{aligned}
& L_{\text {lim it }}=1-\frac{I(z)}{h+I(z)} ; \\
& N_{\text {limit }}=1-\left(1-\frac{q_{\text {min }}}{q(z)}\right)
\end{aligned}
$$

For detailed information on variables, model parameters and initial conditions see Table 1 and Jäger et al. (2010).

However, in addition to Jäger et al. (2010), we consider seasonal mixing by assuming vigorous winter mixing throughout the water column prevailing for a prescribed duration $t_{\text {mix }}$ beginning on day 15 of each year of 365 days $\left(d_{\text {tmix }}=1,000 \mathrm{~m}^{2} \mathrm{day}^{-1}\right.$ at all depth). Transition from winter mixing to mixing under stratified conditions occurs within a day assuming a linear transition in time at each depth. During stratified conditions, we consider profiles of $d$ with vertical variation in mixing intensity $(d=d(z))$, which results in transport terms in Eq. 1 slightly differing from those of Jäger et al. (2010). The profiles of $d$ assume a three-layer system consisting of a surface layer (epilimnion) with thickness $S_{d}$ and mixing intensity $d_{S}$, an intermediate layer of low turbulent mixing (metalimnion) with mixing intensity $d_{l}$ and a deep water layer (hypolimnion) with mixing intensity $d_{D}$. In the simulations with vertically varying diffusivities, we assume that the metalimnion is $5 \mathrm{~m}$ thick and the diffusivity in this layer is $d_{l}=0.5 \mathrm{~m}^{2}$ day ${ }^{-1}$ ( $\mathrm{Li}$ 1973; Lehr and Lehr 2000 and references therein). With these parameters, the exchange velocity between hypolimnion and epilimnion is $0.1 \mathrm{mday}^{-1}$ and corresponds to the value of the parameter $a$ in Jäger et al. (2010) describing the connection of a surface layer to an indefinitely deep water body. The transition between the diffusivities of surface and intermediate and of intermediate and deep layers is linear and occurs within $0.5 \mathrm{~m}$.

The model equations were implemented in MATLAB as in Peeters et al. (2007a), using the method of lines, a second-order spatial discretization of the diffusion equation and a van Leer flux-limiter method for the advection equation. The resulting system of coupled ordinary differential equations is solved by an implicit method with dynamic time stepping (odel5s). The vertical resolution was $0.1 \mathrm{~m}$. All results shown are from the model outcome after 24 years of simulation when a constant seasonality was achieved.

As in Jäger et al. (2010), all state variables were assumed to have a zero flux across the lake surface and a zero diffusive flux across the water-sediment boundary at the bottom of the water column. Sediment arises exclusively from the sedimentation of algae with their bound nutrients out of the water column. The model runs were started with 
Table 1 Definitions of variables, initial conditions and model parameters (adopted from Jäger et al. 2010)

\begin{tabular}{|c|c|c|c|}
\hline \multirow{36}{*}{$\begin{array}{l}\text { bles, initial conditions and mod- } \\
\text { el parameters (adopted from } \\
\text { Jager et al. 2010) }\end{array}$} & Variable & Value & Definition and unit \\
\hline & (a) & & \\
\hline & A & $100^{\mathrm{a}}$ & Algal carbon density $\left(\mathrm{mg} \mathrm{C} \mathrm{m}^{-3}\right)$ \\
\hline & $\mathrm{B}$ & & Algal biomass in the water column $\iint^{2 n d z}\left(\mathrm{mg} \mathrm{C} \mathrm{m}^{-2}\right)$ \\
\hline & $B_{\max }$ & & Seasonal maximum of $B\left(\mathrm{mg} \mathrm{C} \mathrm{m}^{-2}\right)^{0}$ \\
\hline & $B_{\min }$ & & Seasonal minimum of $B\left(\mathrm{mg} \mathrm{C} \mathrm{m}^{-2}\right)$ \\
\hline & $B_{\text {mean }}$ & & Annual mean $B\left(\mathrm{mg} \mathrm{C} \mathrm{m}^{-2}\right)$ \\
\hline & $B_{\text {stead }}$ & & $\begin{array}{l}B \text { at steady state in simulations assuming time-constant } \\
\text { mixing }\left(\mathrm{mg} \mathrm{C} \mathrm{m}^{-2}\right)\end{array}$ \\
\hline & $B_{\text {surt }}$ & & Algal biomass in the surface layer $\int A d z\left(\mathrm{mg} \mathrm{C} \mathrm{m}^{-2}\right)$ \\
\hline & $I$ & & Light intensity ( $\mu$ mol photons $\mathrm{m}^{-20} \mathrm{~s}^{-1}$ ) \\
\hline & $p_{\text {spec }}$ & & Specific algal production rate $\left(\right.$ day $\left.^{-1}\right)$ \\
\hline & $q$ & & Algal nutrient quota (mg $\mathrm{P} \mathrm{mg} \mathrm{C}^{-1}$ ) \\
\hline & $\rho$ & & Specific algal nutrient uptake rate (mg $\mathrm{P} \mathrm{mg} \mathrm{C}^{-1}$ day $^{-1}$ ) \\
\hline & $R_{b}$ & $2.2^{\mathrm{a}}$ & Concentration of particulate nutrients bound in algae $\left(\mathrm{mg} \mathrm{P} \mathrm{m}^{-3}\right)$ \\
\hline & $R_{d}$ & $10-60^{\mathrm{b}}$ & Concentration of dissolved nutrients $\left(\mathrm{mg} \mathrm{P} \mathrm{m}^{-3}\right.$ ) \\
\hline & $R_{d, \text { mean }}$ & & Depth-integrated mean $R_{d}$ for the water column $\left(\mathrm{mg} \mathrm{P} \mathrm{m}^{-3}\right)$ \\
\hline & $R_{d, \text { surr }}$ & & Depth-integrated mean $R_{d d}$ for the surface water layer $\left(\mathrm{mg} \mathrm{P} \mathrm{m}^{-3}\right)$ \\
\hline & $R_{s}$ & $0^{: 3}$ & 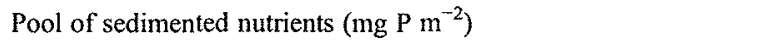 \\
\hline & $R_{\text {troph }}$ & & $\begin{array}{l}\text { Trophic state: total mass of nutrients in the system including } R_{s} \\
\text { per cross-section divided by water column depth }\left(\mathrm{mg} \mathrm{P} \mathrm{m}^{-3}\right)\end{array}$ \\
\hline & $t$ & & Time (day) \\
\hline & $T_{\mathrm{Bmax}}$ & & $\begin{array}{l}\text { Time of the occurrence of } B_{\max } \text { (days elapsed since the onset } \\
\text { of winter mixing) }\end{array}$ \\
\hline & $z$ & & Water depth below the lake surface (meter) \\
\hline & (b) & & \\
\hline & $d$ & $0.01-, 000^{6}$ & Turbulent-diffusion coefficient $\left(\mathrm{m}^{2}\right.$ day $\left.^{-1}\right)$ \\
\hline & $d_{S}, d_{D}$ & $0.01-1,000^{\mathrm{b}}$ & $\begin{array}{l}\text { Turbulent-diffusion coefficient in surface and deep water layer, } \\
\text { respectively }\left(\mathrm{m}^{2} \text { day }{ }^{-1}\right)\end{array}$ \\
\hline & $d_{l}$ & 0.5 & Turbulent-diffusion coefficient in the intermediate layer $\left(\mathrm{m}^{2}\right.$ day $\left.^{-1}\right)$ \\
\hline & $d\left(t_{\operatorname{mix}}\right)$ & 1,000 & Turbulent-diffusion coefficient during winter mixing $\left(\mathrm{m}^{2}\right.$ day $\left.^{-1}\right)$ \\
\hline & $h$ & 120 & $\begin{array}{l}\text { Half-saturation constant of light-dependent algal production } \\
\left(\mu \mathrm{mol} \text { photons } \mathrm{m}^{-2} \mathrm{~s}^{-1}\right)\end{array}$ \\
\hline & $I_{0}$ & $100-600^{b}$ & Light intensity at the surface $\left(\mu \mathrm{mol}\right.$ photons $\left.\mathrm{m}^{-2} \mathrm{~s}^{-1}\right)$ \\
\hline & $k$ & 0.0003 & Specific light-attenuation coefficient of algal biomass $\left(\mathrm{m}^{2} \mathrm{mg} \mathrm{C}^{-1}\right)$ \\
\hline & $k_{\mathrm{bg}}$ & 0.4 & Background light-attenuation coefficient $\left(\mathrm{m}^{-1}\right)$ \\
\hline & $l_{\mathrm{bg}}$ & 0.1 & Specific algal maintenance respiration losses $\left(\right.$ day $\left.^{-1}\right)$ \\
\hline & $m$ & 1.5 & Half-saturation constant of algal nutrient uptake $\left(\mathrm{mgP} \mathrm{m}^{-3}\right)$ \\
\hline & $\mu_{\max }$ & 1.2 & Maximum specific algal production rate $\left(\right.$ day $\left.^{-1}\right)$ \\
\hline & $q_{\max }$ & 0.04 & Maximum algal nutrient quota (mgP $\mathrm{mg} \mathrm{C}^{-1}$ ) \\
\hline & $q_{\min }$ & 0.004 & Minimum algal nutrient quota ( $\mathrm{mgP} \mathrm{mg} \mathrm{C}^{-1}$ ) \\
\hline \multirow{2}{*}{$\begin{array}{l}\text { For the motivation of parameter } \\
\text { choices, see Jäger et al. } 2010\end{array}$} & $r$ & 0.02 & Specific mineralization rate of sedimented nutrients $\left(\mathrm{day}^{-1}\right)$ \\
\hline & $t_{\operatorname{mix}}$ & $20-100^{b}$ & Duration of winter mixing (day) \\
\hline anitial values & $\rho_{\max }$ & 0.2 & 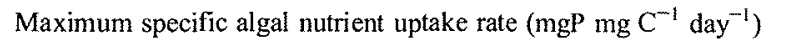 \\
\hline \multirow{2}{*}{$\begin{array}{l}{ }^{b} \text { Range of environmental condi- } \\
\text { tions examined }\end{array}$} & $S_{d}$ & $3-25^{\mathrm{b}}$ & Thickness of the surface layer (m) \\
\hline & v & $0^{c}, 0.25$ & Algal sinking velocity (m day ${ }^{-1}$ ) \\
\hline $\begin{array}{l}\text { Simulations } 53 \text { without } \\
\text { sedimentation }\end{array}$ & $z_{\max }$ & $1-50^{b}$ & $z$ at maximum water column depth $(\mathrm{m})$ \\
\hline
\end{tabular}

$100 \mathrm{mg} \mathrm{Cm}^{-3}, R_{b}=2.2 \mathrm{mg} \mathrm{Pm}^{-3}$ and $R_{d}$ was a value chosen from 10 to $60 \mathrm{mg} \mathrm{Pm}^{-2}$ depending on the nutrient enrichment scenario. 
In the presentation of the results, we consider water column phytoplankton biomass $B=\int_{z \max }^{0} A(z) d z$, surface layer biomass $B_{\text {surf }}=\int_{S \mathrm{~d}}^{0} A(z) \mathrm{dz}$, mean nutrient concentration in the water column $R_{d, \text { mean }}$ and in the surface layer $R_{d \text {,surt }}$ and water column production $P=\int_{z \max }^{0} p_{\mathrm{spec}}(z) A(z) \mathrm{dz}$. In case of seasonally varying conditions, the annual maximum, $B_{\text {max }}$, the annual minimum, $B_{\text {nim }}$, and the annual mean, $B_{\text {mean }}$ of water column biomass, and the annual maximum of water column production, $P_{\max }$, are presented, as well as $R_{d, \text { mean }}$ at $T_{B \max }$, the time of the occurrence of $B_{\max }$ measured relative to the onset of winter mixing. In case of timeconstant diffusivities a steady state develops and $B$ at steady state is identified as $B_{\text {stead. }}$.

\section{Model forcing}

The models consider spatio-temporal mixing conditions typical for monomictic temperate lakes (e.g. Li 1973; Lehr and Lehr 2000), i.e. an intensive period of winter mixing is followed by a stratified period during which a layer of low mixing at intermediate depth resembles a metalimnion characterised by a strong thermocline. The density stratification associated with a thermocline suppresses turbulence and hence leads to reduced mixing (e.g. Fischer et al. 1979; Imboden and Wüest 1995; Lehr and Lehr 2000; EtemadShahidi and Imberger 2006) thereby acting as a bottleneck boundary between surface and deep water (Schwarzenbach et al. 2003). This bottleneck limits upward transport of nutrients from the nutrient-rich hypolimnion to the nutrientpoor epilimnion and also the diffusive downward transport of algae. Our standard model with seasonal forcing considers a 50-m deep water column, seasonal winter mixing with a duration of 50 days with $d_{t \text { mix }}=1,000 \mathrm{~m}^{2}$ day $^{-1}$ and a stratified season after winter mixing with a three-layer structure consisting of a mixed surface layer with $d_{S}=1,000 \mathrm{~m}^{2}$ day ${ }^{-1}$ and thickness $S_{d}$, a 5 -m thick intermediate layer with $d_{l}=$ $0.5 \mathrm{~m}^{2}$ day $^{-1}$ and a deep water layer with $d_{D}=5 \mathrm{~m}^{2}$ day $^{-1}$ ( $d_{D}$ is on the typical order of magnitude as in Lake Zurich: Li 1973). In the standard simulations, $I_{o}=300 \mu \mathrm{mol}$ photons $\mathrm{m}^{-2} \mathrm{~s}^{-1}$ and trophic state $R_{\text {troph }}=32.2 \mathrm{mg} \mathrm{Pm}^{-3} \cdot R_{\text {troph }}$ is defined as the total mass of nutrients in the system per crosssection divided by water column depth.

The results from models considering seasonal mixing $\left(M_{S}\right)$ are compared to steady state solutions of corresponding models $\left(M_{C}\right)$ which do not include winter mixing but assume that the vertical distribution of the diffusivities of $M_{S}$ during the stratified season are constant in time.

The sensitivity of the simulated results to the different transport processes incorporated in the models is investigated by using modifications of $M_{S}$ and $M_{C}$ assuming that (1) the flux of dissolved nutrients $R_{d}$ across the metalimnion is zero $\left(M_{S, \mathrm{RdO},} M_{C, \mathrm{RdO}}\right)$, or (2) the diffusive flux of phytoplankton $A$ and bound nutrients $R_{b}$ across the metalimnion is zero $\left(M_{S}\right.$, ARbo, $\left.M_{C, \mathrm{ARb} 0}\right)$, or (3) the sinking velocity is zero $\left(M_{S, \mathrm{Sed} 0}, M_{C \text {, }}\right.$ Sedo). These three scenarios will be employed to investigate the role of diffusive transport of dissolved nutrients, of diffusive transport of algae with their bound nutrients and of sedimentation for phytoplankton abundance.

The sensitivity of the simulated seasonal course of phytoplankton abundance and production to changes in $S_{c}$, incident light $I_{o}$, duration of winter mixing and trophic state $R_{\text {troph }}$, is studied by numerical experiments considering $S_{d}$ between 3 and $25 \mathrm{~m}$, which is within the range of epilimnion depths reported for very different sized lakes (Boehrer and Schultze 2008), $I_{o}$ between 100 and $600 \mu \mathrm{mol}$ photons $\mathrm{m}^{-2} \mathrm{~s}^{-1}$ and durations of winter mixing between 2 and 100 days. The sensitivity analysis with respect to $R_{\text {troph }}$ covers the range from oligotrophic to meso/eutrophic conditions (10-60 $\mathrm{mg} \mathrm{Pm}^{-3}$ ). Finally, the sensitivity of seasonal phytoplankton development to water column depth is investigated by extending the conditions assumed in Jäger et al. (2010) with seasonal and vertical variation in mixing intensities.

\section{Results}

The seasonally changing mixing conditions in $M_{S}$ with $S_{d}=$ $5 \mathrm{~m}$ result in a seasonal variation in the vertical distribution of phytoplankton and nutrient concentrations that exhibits most features typical for lakes of temperate regions (Fig. 1). Phytoplankton concentrations are low during winter mixing and increase rapidly in the near-surface region when mixing is reduced and the low mixing intensity in the intermediate layer limits export of phytoplankton to larger depth (Fig. la). The rapid increase in phytoplankton concentration is followed by a decline in phytoplankton concentrations resulting in a pronounced maximum in the phytoplankton abundance soon after the onset of phytoplankton growth. Concentrations of dissolved nutrients in the upper $10 \mathrm{~m}$ are maximal at the end of winter mixing and decrease thereafter due to the uptake by phytoplankton (Fig. lb). In the deep water, dissolved nutrient concentrations increase during the stratified season until the onset of winter mixing (Fig. 1b) due to the mineralization of particulate phosphate available from phytoplankton sinking downwards from the euphotic zone. The sinking-out of algaebound particulate phosphate from the mixed surface layer is also visible in the change of the concentration of total phosphorus, $R_{b}+R_{d t}$, especially around day 100 when the phytoplankton bloom in the mixed surface layer leads to a large sedimentation flux of phytoplankton (Fig. 1c). The seasonal variations in water column production and water column phytoplankton biomass are similar in timing (Fig. 1d). Water 
120

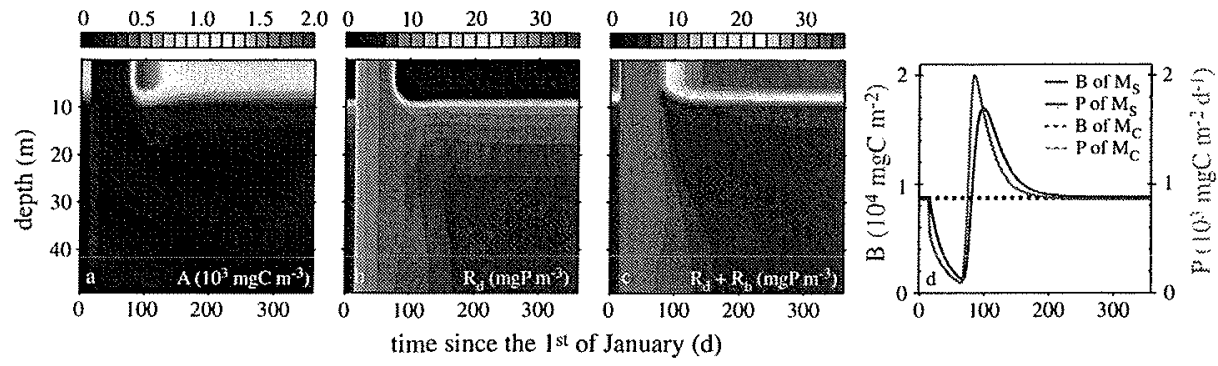

Fig. 1 Seasonal variation in the vertical distribution of a phytoplankton, $\mathbf{b}$ dissolved nutrient concentrations, and $\mathbf{c}$ total nutrient concentration $R_{b}+R_{d}$ in a $50-\mathrm{m}$ deep water column simulated with the model $M_{S}$ that considers seasonal mixing. d Comparison of the seasonal variation in water column biomass and production with the corresponding values at steady state of $M_{C}$ that neglects winter mixing. In $M_{S}$ and $M_{C}$ surface layer thickness $S_{d}=5 \mathrm{~m}, l_{o}=300 \mu \mathrm{mol}$ photons m $\mathrm{m}^{-2} \mathrm{~s}^{-1}$ and $R_{\text {troph }}=32.2 \mathrm{mg} \mathrm{Pm}^{-3}$ column production is minimal during winter mixing and increases rapidly with the onset of stratification. The annual maximum in $P$ occurs slightly before the annual maximum in $B$ and then declines approaching steady state water column production of the model $M_{C}$ (Fig. 1d).

The seasonal pattern in phytoplankton abundance is an important factor contributing to the seasonal pattern in water column production since production equals $p_{\text {spec }} \cdot A$. Note that the seasonal course in phytoplankton abundance not only depends on $p_{\text {spec }}$ at a given depth but additionally on mixing altering the vertical position of phytoplankton in the light gradient. However, specific production at a given depth changes over the season, indicating that the factors limiting phytoplankton production at a given depth change seasonally (Fig. 2c). During winter mixing light limitation and nutrient limitation are both significantly smaller than during the rest of the season and at steady state in $M_{C}$ (Fig. $2 \mathrm{~d}, \mathrm{e}, \mathrm{i}, \mathrm{j}, \mathrm{n}, \mathrm{o}$ ). Hence, maximal specific production rates occur in the upper water layers during winter mixing when phytoplankton concentrations are at their annual minimum. However, these large specific growth rates do not result in phytoplankton growth because winter mixing leads to pronounced vertical transport of phytoplankton in the gradient of the light climate and consequently to light-limited water column biomass production. After the onset of stratification, nutrient limitation in the seasonally mixed systems is substantially smaller than at steady state in $M_{C}$, and remains smaller until the nutrients are significantly depleted by the development of the seasonal algae peak (Fig. 2e). At the seasonal algae peak and thereafter, light limitation is larger in the seasonally mixed model than at steady state in $M_{C}$ because of self-shading by the phytoplankton (Fig. 2i, n). Specific production thus decreases after the

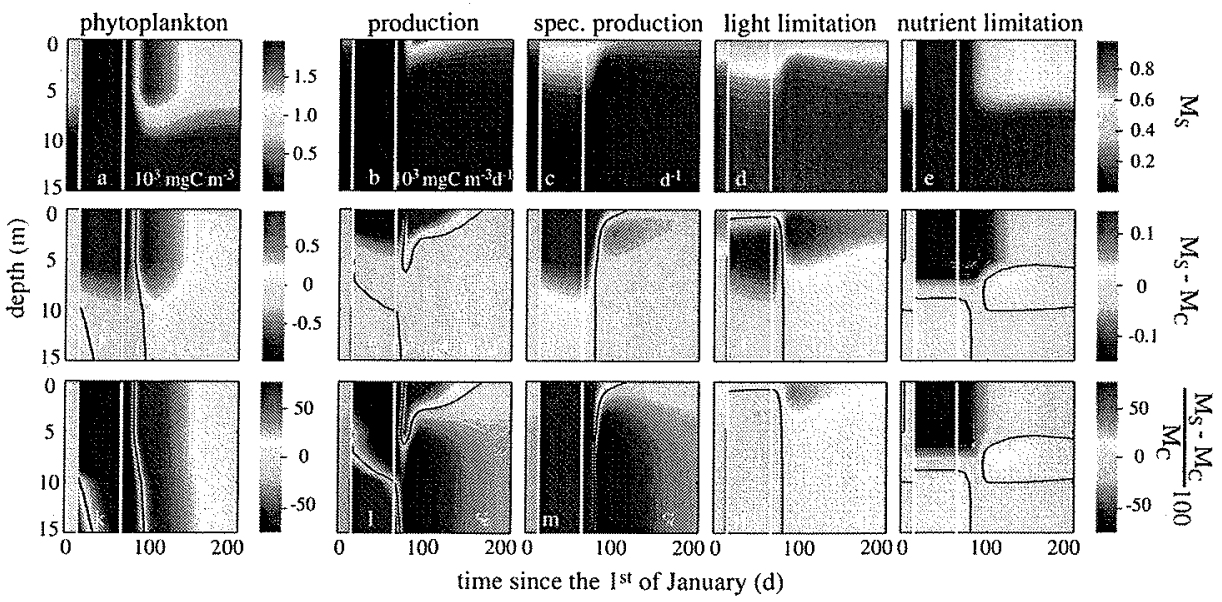

Fig. 2 Temporal changes in the vertical distribution of phytoplankton concentration $A(z)$, production $p_{\text {spcc }}(z) \cdot A(z)$, specific production $p_{\text {spec }}(z)$, light limitation and nutrient limitation as simulated with the model $M_{S}(\mathbf{a}-\mathbf{e})$. Colour bar units are provided in each sub-panel. The winter mixing period is indicated by white vertical lines. The difference between simulation results assuming seasonal mixing using scenario $M_{S}$ and simulation results with time constant diffusivities using scenario $M_{C}$ are depicted in $\mathbf{f}-\mathbf{j}$ (units as in $\mathbf{a}-\mathbf{e}$ ). Percent differences between results from simulations with $M_{S}$ and $M_{C}$ are shown in k-o. The black lines (f-0) indicate zero deviation between results from $M_{S}$ and $M_{C}$. Note that during the first 15 days of the year the results from scenario $M_{S}$ with seasonal mixing (a-e) closely agree with the results at steady state of scenario $M_{C}$. The simulations consider a $50-\mathrm{m}$ deep water column of which only the top $15 \mathrm{~m}$ are shown. Surface layer thickness $S_{d}=5 \mathrm{~m}, I_{o}=300 \mu \mathrm{mol}$ photons $\mathrm{m}^{-2} \mathrm{~s}^{-1}$ and $R_{\text {tropli }}=$ $32.2 \mathrm{mg} \mathrm{Pm}^{-3}$ 
end of winter mixing and eventually becomes even smaller than specific production at steady state in $M_{C}$. Phytoplankton abundance, production, specific production and limitation in the seasonally mixed model differ substantially from the corresponding properties at steady state in $M_{C}$, with deviations typically exceeding $50 \%$ during much of the year and in a large part of the water column (Fig. $2 \mathrm{k}, 1, \mathrm{~m}, \mathrm{n}, \mathrm{o}$ ).

The thickness of the surface layer is an important factor influencing seasonal variation in phytoplankton biomass and nutrient abundance in the water column and especially in the surface layer (Fig. 3). With increasing surface layer thickness, $B_{\max }$ increases reaching a maximum at $S_{d}=10 \mathrm{~m}$ and decreases again when $\mathrm{S}_{d}$ is further increased (Fig. 3e). The unimodal dependence of $B_{\max }$ on $S_{d}$ results from opposing effects linked to $S_{d}$. With increasing $S_{d}$, the accessible pool of nutrients increases and supports higher phytoplankton biomass, whereas light limitation of phytoplankton mixed over a larger depth range increases and reduces water column production. Additionally, the relative importance of the effects of phytoplankton transport changes with $S_{d}$, since concentrations and gradients and thus also sedimentation and diffusive flux of phytoplankton across the metalimnion typically decrease with increasing $S_{d}$. The thicker the surface layer the later reaches phytoplankton biomass the annual maximum (Fig. $3 \mathrm{~g}$ ). Shortly before $T_{B \text { max }}$, dissolved nutrients show a minimum (Fig. 3c) and become very low or even completely depleted in the surface layer (Fig. 3d). Note that the rapid decline of $R_{d, \text { mean }}$ after the onset of winter mixing (Fig. 3c) is accompanied by a rapid increase in $R_{b \text {,mean }}$ (not shown) but not in phytoplankton biomass, because the rate of nutrient uptake is much higher than its conversion to production under the severe light limitation during winter mixing. The subsequent increase in $R_{t, \text { mean }}$ during the winter mixing period (Fig. $3 \mathrm{c}$ ) arises from the decline in water column biomass and the associated release of stored nutrients.

As $B_{\max }$ in the seasonally mixed model, $B_{\text {stead }}$ in the model without winter mixing shows an unimodal dependence on $S_{d}$ (Fig. 3f). The mixed layer depth $S_{d}$ at which $B_{\text {stead }}$ in $M_{C}$ becomes maximal is slightly larger than the $S_{d}$ at which $B_{\max }$ in $M_{S}$ becomes maximal. At small $S_{d} B_{\max }$ is larger than $B_{\text {stead }}$ but at $S_{d}=25 \mathrm{~m} B_{\max }$ and $B_{\text {stead }}$ have essentially the same value. In fully mixed systems with time constant mixing, steady-state phytoplankton biomass also showed an unimodal dependence on water column depth (Huisman and Weissing 1995; Diehl 2002). This functional dependence of steady-state phytoplankton abundance on water column depth was explained by an increased importance of sedimentation losses in systems with shallow water depth and by reduced production due to increased light limitation in systems with large water depth (Diehl 2002). The same arguments explain the dependence of $B_{\text {stead }}$ on $S_{d}$ in the simulations with time-constant mixing (Fig. 3f),
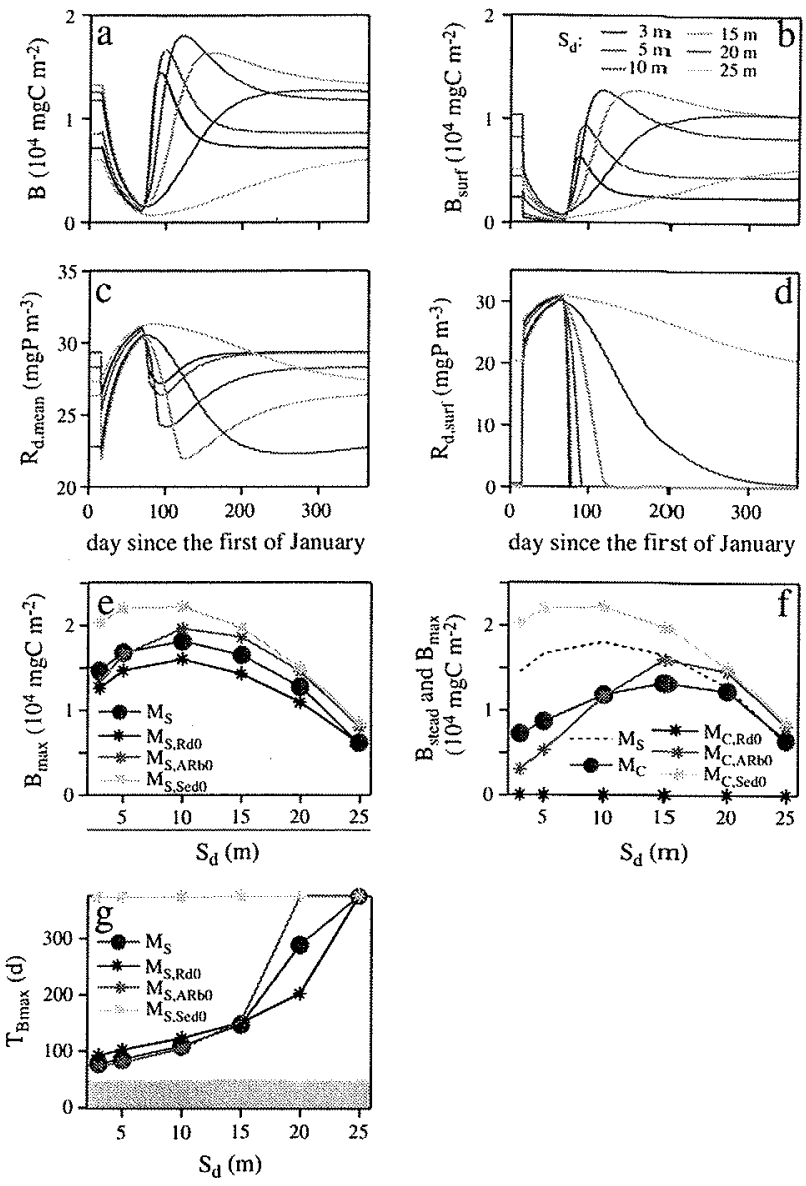

Fig. 3 The impact of surface layer thickness $S_{d}$ and transport processes on timing and size of the seasonal phytoplankton peak. The typical seasonal patterns of the integrated phytoplankton biomass $(\mathbf{a}, \mathbf{b})$ and the mean nutrient concentration $(c, d)$ in the entire water column $(a, c)$ and in the surface layer $(b, \mathbf{d})$ depend on $S_{k}$. The role of different transport processes for model outcome $(\mathbf{e}-\mathbf{g})$ were investigated by simulations assuming (1) zero diffusive flux of dissolved nutrients across the metalimnion $\left(M_{S, R d o}, M_{C, R d o}\right),(2)$ zero diffusive flux of phytoplankton and $R_{b}$ across the metalimnion $\left(\mathrm{M}_{\mathrm{S}, \mathrm{ARb} 0}, M_{C, \mathrm{ARb}}\right)$, (3) zero sedimentation of phytoplankton and $R_{b},\left(M_{S, S e d 0}, M_{C, S e d 0}\right)$. Simulations that consider seasonal mixing, i.e. scenarios $M_{S}$, are depicted in e and $\mathbf{g}$, whereas steady state solutions for models without winter mixing, i.e. scenarios $M_{C}$, are shown in $\mathbf{f}$. The grey bar in $\mathrm{g}$ indicates the 50-day time period of winter mixing. In all simulations is $t_{\operatorname{mix}}=$ 50 days, $I_{o}=300 \mu$ mol photons $\mathrm{m}^{-2} \mathrm{~s}^{-1}$ and $R_{\mathrm{troph}}=32.2 \mathrm{mg} \mathrm{Pm}^{-3}$

whereas in the simulations with seasonal mixing sedimentation losses from the mixed layer are not as important but the reduced production due to the lower total amount of nutrients initially available in the epilimnion contributes to the reduced $B_{\max }$ at shallow $S_{d}$.

$B_{\max }$ not only depends on the thickness of the surface layer but also on the diffusivity within this layer. If $S_{d} \leq 10 \mathrm{~m} B_{\max }$ is essentially independent of $d_{S}$ as long as $d_{S} \geq 10 \mathrm{~m}^{2}$ day ${ }^{-1}$, whereas for $S_{d}>10 \mathrm{~m} B_{\text {max }}$ is maximal at $d_{S}$ of about $10 \mathrm{~m}^{2}$ day ${ }^{-1}$ and is smaller for larger and smaller $d_{S}$ (Electronic supplementary 
material (ESM) Fig. Ola). When $d_{S} \leq 50 \mathrm{~m}^{2} \mathrm{day}^{-1}$ in the surface layer, phytoplankton biomass shows a distinct seasonal peak before the onset of winter mixing even at the largest $S_{d}$ (ESM Fig. Olb, c), but not so in simulations with $d_{S}=1,000 \mathrm{~m}^{2} \mathrm{day}^{-1}$ (Fig. 3b, g) when the slow increase in $B$ is finally terminated by the onset of the winter mixing, i,e before nutrient limitation becomes sufficient to cause a decline in $B$.

\section{Sensitivity to transport processes}

Compared to simulations employing $M_{S}, B_{\max }$ is lower for $M_{S, \mathrm{Rd} 0}$, higher for $M_{S, \mathrm{ARb} 0}$ except if $S_{d}=3 \mathrm{~m}$, and higher for $M_{S \text { Sedo }}$ (Fig. 3e). These deviations between the results from the different mixing scenarios indicate that the phytoplankton abundance in the seasonally mixed system profits from the diffusive transport of dissolved nutrients but suffers from diffusive transport of phytoplankton cells and their bound nutrients (except for shallow surface-mixed layers) and from sedimentation losses. In $M_{S, \text { ARbo }}$, the effect of the diffusive transport of phytoplankton and of the algae-bound nutrients on phytoplankton abundance depends on $S_{d}$ because at large $S_{d}$ diffusion causes an export of phytoplankton from the productive zone, whereas at small $S_{d}$ diffusion results in an upward flux of phytoplankton and of stored nutrients allowing for additional production. In scenario $M_{S \text { S Sed0, the rapid increase in phytoplankton biomass after }}$ seasonal mixing is not followed by a decline but by a slight increase in biomass until winter mixing sets in (Fig. $3 \mathrm{~g}$ ). Apparently, the development of a phytoplankton bloom in the model requires sedimentation which is consistent with the close agreement between $B_{\max }$ in the seasonally-mixed scenario $M_{S \text { S Sedo }}$ and $B_{\text {stead }}$ in the scenario $M_{C \text { Sedo }}$ (Fig. 3e, f).

However, the modifications in vertical transport assumed in the different scenarios have a larger influence on $B_{\text {stead }}$ in simulations without winter mixing $\left(M_{\mathrm{C}, \mathrm{Rd} 0}, M_{C, \mathrm{ARb} 0}\right.$, and $M_{C \text { Sedo }}$ in Fig. $3 \mathrm{f}$ ) than on $B_{\max }$ in seasonally-mixed systems (Fig. 3e). Without winter mixing, phytoplankton becomes even extinct if the diffusive flux of $R_{d}$ across the metalimnion is zero (Fig. 3f $M_{C, \mathrm{RdO}}$ ).

\section{Sensitivity to forcing factors}

Phytoplankton biomass not only depends on $S_{d}$ and $d_{s}$, i.e. on the vertical distribution of mixing intensity, but also on surface light intensity $I_{o}$ and trophic state $R_{\text {troph }}$ (Fig. 4). $R_{\text {troph }}$, i.e. the total mass of nutrients in the system (including $R_{b}, R_{d}$ and $R_{S}$ ) per cross-section divided by water column depth, very closely agrees with the mean water column concentration of dissolved and particulate nutrients $\left(R_{b}+\right.$ $R_{d}$ ) before onset of stratification, i.e. at day 65 . If the surface layer thickness is $S_{d}=5 \mathrm{~m}, B_{\max }$ in the seasonally-mixed system, $M_{S}$, increases strongly with increasing $I_{o}$, whereas the effect of $I_{o}$ on $B_{\text {stead }}$ in $M_{C}$ levels off fast (Fig. $4 \mathrm{~g}$ ). Note that at $I_{o} \leq 200 \mu \mathrm{mol}$ photons $\mathrm{m}^{-2} \mathrm{~s}^{-1}$ and $S_{d}=20 \mathrm{~m}, B_{\max }$ is less than $B_{\text {stead }}$ suggesting that phytoplankton survival requires higher $I_{o}$ in the seasonally-mixed system with $S_{d}=$ $20 \mathrm{~m}$ than in the corresponding model without winter mixing (Fig. $4 \mathrm{~g}$ ). With respect to trophic state, $B_{\max }$ in $M_{S}$ and $B_{\text {stead }}$ in $M_{C}$ both increase at a similar rate and almost linearly with $R_{\text {troph }}$ (Fig. $4 \mathrm{i}$ ). If the surface layer thickness is $S_{d}=20 \mathrm{~m}$, both, $B_{\max }$ in $M_{S}$ and $B_{\text {stead }}$ in $M_{C}$ increase strongly with $I_{o}$ and are rather insensitive to nutrient enrichment (Fig. 4h, j).

Altering the duration of the winter-mixing period in a seasonally-mixed system with $S_{d}=5 \mathrm{~m}$ has essentially no affect on $B_{\max }$ but leads to a significant shift in the timing of $B_{\max }$ (Figs. $4 \mathrm{e}, \mathrm{k}$ and 5 ) because it delays the termination of winter mixing. Winter mixing durations as short as 2 days
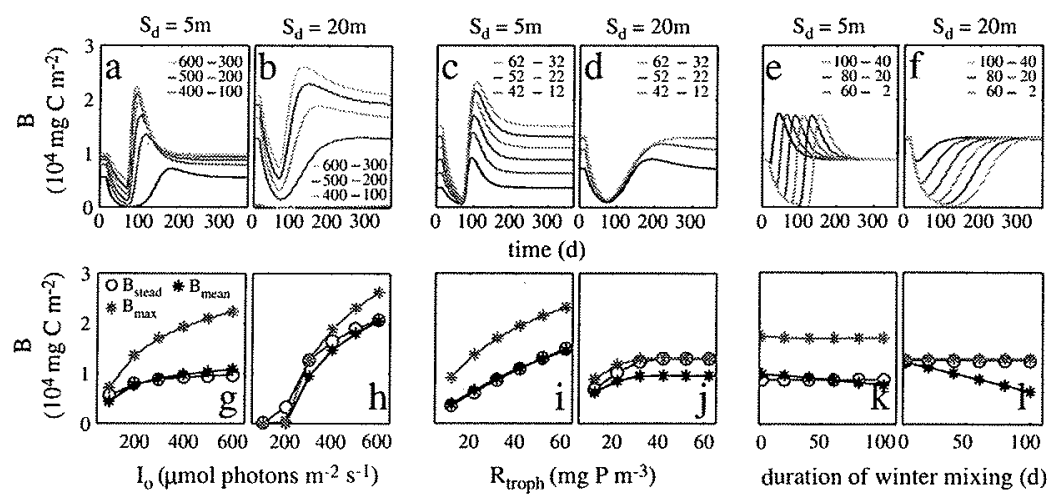

Fig. 4 Sensitivity of water column biomass to incident light $(\mathbf{a}, \mathbf{b}, \mathbf{g}$, h), trophic state $(\mathbf{c}, \mathbf{d}, \mathbf{i}, \mathbf{j})$ and duration of winter mixing $(e, \mathbf{f}, \mathbf{k}, \mathbf{l})$. a-f The seasonal course of $B$ for different abiotic conditions, whereas gI depict $B_{\max }$ and the annual mean of $B, B_{\text {meam }}$ of simulations with seasonal mixing $M_{S}$ and $B_{\text {stead }}$ of simulations without winter mixing $M_{C}, B, B_{\max }, B_{\text {mcan }}$, and $B_{\text {stead, }}$, respectively, were simulated using the

same parameters in $M_{S}$ and $M_{C}$. Except for the parameter of the sensitivity analysis of the particular panel $I_{\sigma}=300 \mu \mathrm{mol}$ photons $\mathrm{m}^{-2} \mathrm{~s}^{-1}, R_{\mathrm{troph}}=32.2 \mathrm{mg} \mathrm{P} \mathrm{m}{ }^{-3}$ and the duration of winter mixing in $M_{S}$ was $t_{\mathrm{mix}}=50$ days. Note, that $S_{d}=5 \mathrm{~m}$ in a, c, e, g, i, $\mathrm{k}$, whereas $S_{d}=$ $20 \mathrm{~m}$ in $\mathbf{b}, \mathbf{d}, \mathbf{f}, \mathbf{h}, \mathbf{j}, \mathbf{l}$ 
Fig. 5 Sensitivity of the timing of $B_{\max }$ to incident light (a), trophic state (b), timing of the onset of stratification (c) and overwintering biomass (d) for $S_{d}=5 \mathrm{~m}$ and $S_{d}=20 \mathrm{~m}$. The grey area in the panels $\mathbf{a}, \mathbf{b}$, and $\mathbf{c}$ indicates the time period of winter mixing. In d, the timing of $B_{\max }$ is measured relative to the onset of stratification. $T_{B \text { max }}$ is not shown for $S_{d l}=20 \mathrm{~m}$ and $I_{o}=100 \mu \mathrm{mol}$ photons $\mathrm{m}^{-2} \mathrm{~s}^{-1}$ because under these conditions phytoplankton becomes extinct. Note, that $\mathbf{d}$ is based on the model scenarios with different durations of winter mixing: The longer the duration of winter mixing the lower $B_{\min }$
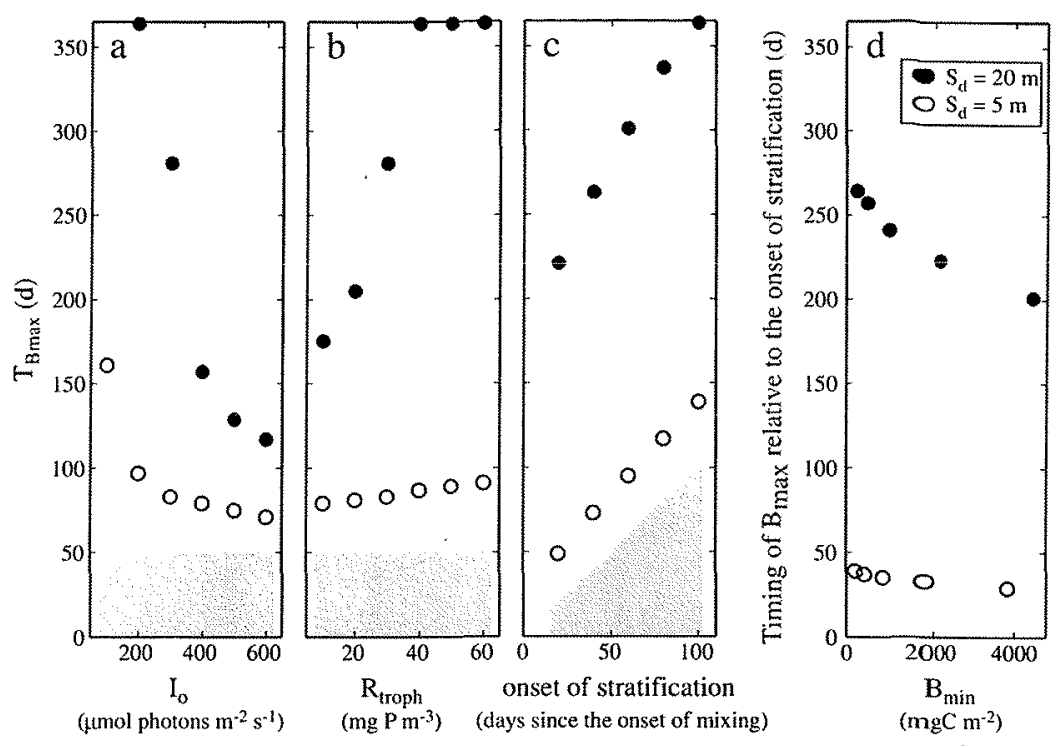

are sufficient to induce the typical seasonal development of the phytoplankton abundance (Fig. 4) suggesting that the conclusions from this study not only apply to monomictic lakes but also to dimictic lakes between the beginning of spring mixing and the onset of autumn mixing.

If $S_{d}=20 \mathrm{~m}, B_{\max }$ is essentially independent of the duration of winter mixing as in the case with $S_{d}=5 \mathrm{~m}$, but the annual peak develops substantially later than in the case of $\mathrm{S}_{d}=5 \mathrm{~m}$ (Fig. $5 \mathrm{c}$ ) and $B_{\max }$ is only slightly larger than $B$ immediately before the onset of winter mixing (Fig. 4f, 1).

In all simulations with $S_{d}=5 \mathrm{~m}, B_{\max }$ is substantially larger than $B_{\text {stead, }}$, whereas in the simulations with $S_{d}=20 \mathrm{~m}, B_{\max }$ and $B_{\text {stead }}$ are similar. The annual mean $B$ in $M_{S}, B_{\text {mean }}$, and $B_{\text {stead }}$ have similar values if $S_{d}=5 \mathrm{~m}$. This agreement however results from averaging large positive deviations between $B$ in $M_{S}$ and in $M_{C}$ during the stratified period with large negative deviations during the time period of strong winter mixing. Nevertheless, in the simulations with $S_{d}=5 \mathrm{~m}, B_{\text {stead }}$ not only closely resembles $B_{\text {mean }}$ but also shows a similar sensitivity to external forcing factors, e.g. to incident light and trophic state (Fig. $4 \mathrm{~g}$, $i, k$ ). Hence, in systems with a shallow mixed-surface layer, the steady state phytoplankton abundance in models with timeconstant mixing can be used as approximation for the annual mean phytoplankton abundance in the corresponding models with seasonal mixing. This however is not valid for systems with large surface-mixed layers, as in the cases with $S_{d}=20 \mathrm{~m}$ $B_{\text {mean }}$ is smaller than $B_{\text {stead }}$ (Fig. $4 \mathrm{~h}, \mathrm{j}$ ) and the difference between $B_{\text {mean }}$ and $B_{\text {stcad }}$ increases with increasing duration of winter mixing to more than $100 \%$ of $B_{\text {mean }}$ (Fig. 41 ).

When the duration of winter mixing differs (Fig. 5c), phytoplankton peak timing relative to the onset of winter mixing is delayed at $S_{t l}=5 \mathrm{~m}$ almost in parallel with the delay in the termination of winter mixing, or equivalently, with the delay in the onset of stratification. However, the slope in this relationship is larger than 1 indicating that with increasing mixing duration the time between the onset of stratification and the phytoplankton maximum slightly increases. With $S_{d}=20 \mathrm{~m}$ an increase in mixing duration results in an increasingly stronger delay of peak timing relative to the termination of winter mixing. The delay of peak timing relative to mixing termination results from the lower over-wintering abundance associated with a longer duration of winter mixing (Fig. 5d). Compared to the changes in $T_{B \text { max }}$ associated with the mixing duration scenarios, forward shifts in $T_{B \max }$ due to increasing light intensity (Fig. 5a) and delays of $T_{B \max }$ due to nutrient enrichment (Fig. 5b) are small, if the surface-mixed layer is small, i.e. at $S_{d}=5 \mathrm{~m}$. However, at $S_{d}=20 \mathrm{~m}$ decreasing the light intensity from 400 to $300 \mu \mathrm{mol}$ photons $\mathrm{m}^{-2} \mathrm{~s}^{-1}$ or increasing $R_{\text {troph }}$ from 30 to $40 \mathrm{mg} \mathrm{Pm}^{-3}$ leads to a delay in $T_{B \max }$ of 124 and 83 days, respectively, which is larger than the delay caused by shifting the onset of stratification by 40 days (Fig. 5). A delay in the timing of the phytoplankton peak in systems with larger mixing depth or lower incident light intensities was also observed in simulations investigating the transient dynamics of phytoplankton and was explained by slower phytoplankton production in these systems due to increased light limitation (Diehl et al. 2005).

\section{Phytoplankton development and water column depth}

The consequences of seasonal changes in vertical mixing for phytoplankton abundances in water columns with different depths are investigated by comparing steady state solutions for systems with temporally constant diffusivities that either are spatially constant, $d=$ const., or vary with depth, $d(z)$, with simulation results for systems that additionally consider winter mixing by assuming temporally varying diffusivities. During 
the stratified period, the time-dependent diffusivities are either spatially constant $d(t)$ or vary with depth, $d(t, z)$.

The simulations with $d=$ const. using the parameter values of Jäger et al. (2010) confirm the results of the earlier study and the validity of our numerical procedure (Fig. 6a, e, i) Phytoplankton becomes extinct when lake depths and $d$ are large, phytoplankton biomass is small when mixing intensity is small and becomes maximal for $d=10 \mathrm{~m}^{2}$ day ${ }^{-1}$ (Fig. 6a). Introducing seasonal variation in mixing intensity by assuming winter mixing with a duration of 50 days and $d_{t \mathrm{mix}}=$ $1,000 \mathrm{~m}^{2}$ day $^{-1}$ results in significantly higher $B_{\max }$ at large water depth and low mixing intensities for $d=d(\mathrm{t})$ than for $d=$ const (Fig. 6b). In simulations with large mixing intensities, i.e. $d=100 \mathrm{~m}^{2}$ day $^{-1}$ and $d=1,000 \mathrm{~m}^{2}$ day $^{-1}$, phytoplankton becomes extinct in water columns of similar water depths independent of choosing $d=$ const or $d=d(t)$ (Fig. 6a, b).

Reconsidering temporally constant diffusivities but assuming that $d$ varies in the vertical $d=d(\mathrm{z})$ by adding a $5-\mathrm{m}$ thick intermediate layer $\left(d_{I}=0.5 \mathrm{~m}^{2}\right.$ day $\left.^{-1}, S_{d}=5 \mathrm{~m}\right)$ increases the persistence range of phytoplankton (Fig. 6c). In contrast to the simulations without a metalimnion, phytoplankton does not

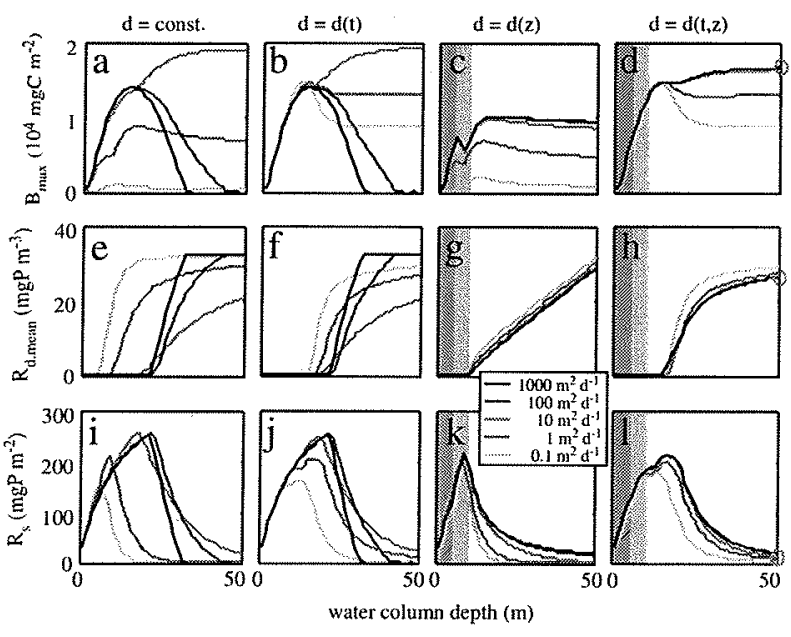

Fig. 6 Consequences of water column depths and mixing intensity on phytoplankton and nutrient concentrations in models assuming constant $(d=$ const. $)$ and temporally $(d=d(t))$, spatially $(d=d(z))$ and temporally and spatially $(d=d(t, z))$ varying mixing intensities. $B_{\max }$ is depicted in a d. Mean nutrient concentration (e-h) and the pool of nutrients in the sediments $(i-1)$ are shown for the time when $B=B_{\max }$. Lines of same colour indicate simulations with the same $d_{S}=d_{D}$ (see panel $\mathbf{k})$. In the simulations with spatially varying $d$, i.e. $d(z)$ and $d(z, t)$, an intermediate layer with $d_{l}=0.5 \mathrm{~m}^{2} \mathrm{~s}^{-1}$ was introduced between 5 and $10 \mathrm{~m}$ water depth whereas in the other simulations $d_{I}=d_{S}=d_{D}$. The intermediate layer of low diffusivity $d_{l}$ has no influence on simulations in water columns with depths $\leq 5 \mathrm{~m}$ (dark grey regions) and is only partly developed in water columns with depths between 5 and $10 \mathrm{~m}$ (light grey regions). In the simulations with temporally varying $d$, seasonal mixing was considered by applying $d\left(t_{\text {mix }}\right)=1,000 \mathrm{~m}^{2}$ day $^{-i}$ in the entire water column between day 15 and 65 of each year of 365 days. Model results considering a $50-\mathrm{m}$ deep water column assuming $d=d(t, z)$ with $d_{S}=1,000 \mathrm{~m}^{2} \mathrm{~s}^{-1}$ and $d_{D}=5 \mathrm{~m}^{2} \mathrm{~s}^{-1}$ are depicted as circles $(\mathbf{d}, \mathbf{h}, \mathbf{l})$ become extinct even at the largest water depths and largest surface- and deep-water mixing intensities considered. Instead, the largest mixing intensities support the highest $B_{\max }$.

In simulations in which both vertical and seasonal variation of $d$ were introduced, $d=d(t, z)$, phytoplankton does not become extinct and $B_{\max }$ only weakly depends on the value of $d$ in surface and deep water layer (Fig. 6d). For a 50-m deep water column, simulations assuming $d_{S}=1,000 \mathrm{~m}^{2}$ day ${ }^{-1}$ and $d_{i}=5 \mathrm{~m}^{2}$ day $^{-1}$ as in $M_{S}$ result in essentially the same $B_{\max }$ as simulations in which $d_{S}=d_{D} \geq 10 \mathrm{~m}^{2}$ day $^{-1}$ (Fig. 6d). In the simulations in which $d$ varies with depth, $B_{\max }$ becomes considerably larger if seasonal mixing is considered, i.e. $d=$ $d(t, z)$ (Fig. 6c, d).

In the seasonally-mixed systems, considering a metalimnion with low mixing intensity during the stratified period, $B_{\max }$ is rather insensitive to total water column depth and to the mixing intensity in the surface and deep layers during the stratified period (Fig. 6d). This is reasonable, because in deep systems with strong vertical mixing, a metalimnion with low mixing intensity supports phytoplankton abundance by preventing downward transport of phytoplankton to depths with strong light limitation (Fig. 6c) and in systems with weak mixing during the stratified period, seasonal mixing supports phytoplankton abundance by replenishing dissolved nutrients in the upper-mixed layer (Fig. 6b).

The insensitivity of $B_{\max }$ to mixing intensity in surface and deep layers in the scenarios $d=d(t, z)$ implies that in these scenarios nutrient uptake rates and sedimentation rates are similar for different mixing intensities. This explains why at the same water column depth $R_{d \text { mean }}$ and $R_{s}$, respectively, deviate much less for different mixing intensities in the scenario $d=d(t, z)$ than for $d=$ const (Fig. 6e-1). Note, that $R_{s}$ declines with increasing water column depths (Fig. 6i-1) because in deep water columns, most of the sinking particulate nutrients are mineralized before they reach the sediment.

\section{Discussion}

The results from the models considering seasonal variation in vertical distribution and intensity of mixing differ significantly from the steady-state conditions obtained in models assuming time-constant mixing. Water column production, phytoplankton abundances, and nutrient concentrations in seasonallymixed systems (scenario $M_{S}$ ) and in corresponding systems without winter mixing (scenario $M_{C}$ ) are only comparable at the end of summer, just prior to winter mixing (Figs. 1, 2 and 3). A detailed quantification of the differences between the results from the scenarios $M_{S}$ and $M_{C}$ is provided in the ESM (Figs. $\mathrm{O} 2$ and $\mathrm{O} 3$ ).

The time scale required to reach conditions that closely resemble steady-state depends especially on processes which involve feedback mechanism operating throughout 
the water column, i.e. consumption, remineralization and transport (sedimentation and mixing) of nutrients and the response of nutrient-limited phytoplankton distributions. In contrast, the response of phytoplankton abundance to processes associated with light assimilation are much faster, because feedback mechanisms (e.g. self shading) mainly depend on the upper water layers and the response of the underwater light climate to changes in phytoplankton abundance is instantaneous. This suggests that deviations from steady-state conditions due to seasonal mixing should be larger in systems where nutrient limitation plays a role (e.g. Jäger et al. 2010 and this study) than in purely light-limited systems (e.g. Huisman et al. 2002).

Processes determining the abundance of phytoplankton in the water column abundance and the role of the mixed-layer depth

A major difference in the control of phytoplankton production in models with and without seasonal mixing arises from differences in the spatio-temporal patterns of nutrient supply: whereas the steady-state biomass in time-constant environments predominantly depends on the resources provided by the diffusive flux from the hypolimnion through the metalimnion, the biomass and production in the simulations with seasonal mixing are strongly influenced by the nutrient pool available after winter mixing. At steady state in systems with time-constant mixing (scenario $M_{C}$ ), all nutrients supplied by mixing across the metalimnion are taken up and consumed in the surface layer at the same rate as they are transported. If the flux of dissolved nutrients across the metalimnion is zero as in $M_{C, \mathrm{R} d 0}$, phytoplankton production will be essentially restricted to deeper water where light intensity may not be sufficient to support survival of the phytoplankton population (Fig. $3 f M_{C, \mathrm{Rd} 0}$ ). In systems with seasonal mixing, the annually renewed nutrient pool available after winter mixing is a major source of nutrients utilised by phytoplankton and explains why phytoplankton does not become extinct in scenario $M_{S, \mathrm{Rd} 0}$, that considers seasonal mixing but assumes zero flux of dissolved nutrients through the metalimnion during the stratified season (Fig. 3e).

The exploitation of the annually renewed nutrient pool by the growing phytoplankton population (in the following called pool exploitation) is the main factor determining the nutrient concentration in the euphotic zone and thus has a strong effect on seasonal changes in production and phytoplankton biomass (Figs. 2 and 3). The utilisation of a resource pool for phytoplankton production may result in the development of a phytoplankton peak, as pool exploitation may eventually exhaust the nutrient pool in the euphotic zone and the diffusive flux of nutrients from below is not sufficient to support the standing stock of phytoplankton resulting in a decline in biomass. Whether a seasonal peak in phytoplankton biomass can develop before the onset of winter mixing, thus depends on the size of the nutrient pool and on the rate of its exploitation in relation to the rates of production and losses of phytoplankton.

The rate of pool exploitation is determined by the standing stock and the specific growth rate of phytoplankton, the accessible nutrient pool and by the supply of nutrients from the diffusive nutrient flux. All these factors change seasonally. With increasing depth of the mixed surface layer $S_{d}$, light limitation of the phytoplankton mixed over a larger depth range leads to a reduced growth rate of phytoplankton (e.g. Diehl 2002) but the accessible nutrient pool increases. Hence, the rate of exploitation of the nutrient pool decreases and the time required for the development of a phytoplankton peak increases with mixed-layer depth and may even extend over the entire season (Fig. $3 \mathrm{~g}$ ). In the latter case (mixed-layer depth $S_{d}=25 \mathrm{~m}$ ), the timing of the occurrence of the peak abundance is not determined by the exhaustion of the resource pool but by the onset of the winter mixing period. However, reducing surface layer mixing to $d_{s}=$ $10 \mathrm{~m}^{2} \mathrm{day}^{-1}$ increases the specific growth rate, thus also the rate of pool exploitation, and a seasonal peak can develop also at a mixed-layer depth of $S_{l l}=25 \mathrm{~m}$ (ESM Fig. O1).

In our model, sedimentation is essential for the development of a seasonal peak, as without sedimentation losses, phytoplankton biomass continues to grow until the onset of winter mixing (see Fig. $3 \mathrm{~g}, M_{S, \mathrm{Sed} 0}$ ). In all our simulations shown in Fig. 4, only a single phytoplankton peak developed during the season without further oscillations. This absence of oscillatory behaviour differs from results by Huppert et al. (2002) for nutrient-limited phytoplankton with fixed stoichiometry in a simplified one-box model. In our vertically resolved model, the transitions in phytoplankton abundance remain smooth with a single seasonal peak, independent of whether the stoichiometry is flexible or fixed (results for fixed stoichiometry see ESM Fig. O4), and whether light shading by phytoplankton is considered or not (not shown). Only if the vertical diffusivity is reduced to a very low value of $0.1 \mathrm{~m}^{2}$ day ${ }^{-1}$ throughout the entire water column during stratified conditions, the phytoplankton abundance in a $50-\mathrm{m}$ water column shows damped oscillations after winter mixing. This suggests that the different dynamic properties of the seasonal phytoplankton development in our model and in the model of Huppert et al. (2002) most likely arise from the resolved vertical dimension in our model that (a) allows for a consistent calculation of nutrient and phytoplankton fluxes from vertical mixing, whereas nutrient fluxes were prescribed boundary conditions in Huppert et al. (2002), and (b) enables the consideration of light limited production in a vertical light gradient.

In real systems, phytoplankton is not only controlled by bottom up processes but also by top-down processes. Herbivorous zooplankton increases the loss rate of phytoplankton and thus additionally contributes to the generation of the 
seasonal peak in phytoplankton biomass. In our bottom-up controlled phytoplankton model, only one seasonal peak developed (see above), but no clear water phase typical for seasonally stratified lakes (Sommer et al. 1986), suggesting that the occurrence of a clear water phase may require zooplankton grazing. This is supported by simulations of the transient dynamics of phytoplankton which shows a clear water phase if Daphnia grazing is considered (Jäger et al. 2008). Including zooplankton necessitates simulation of further details on the abiotic environment, e.g. in case of daphnids seasonal variation in water temperature is a key factor for population growth (Schalau et al. 2008).

Sensitivity of phytoplankton abundance to nutrient enrichment and incident light intensity

The size of the nutrient pool and the processes controlling its exploitation explain why the response of water column biomass to changes in incident light intensity, nutrient loading and the vertical distribution of mixing intensities differs between time-constant and seasonally varying mixing scenarios. If the surface-mixed layer is shallow, light intensities within the surface-mixed layer are high and the standard value for the intensity of incident light $\left(I_{o}=300 \mu \mathrm{mol}\right.$ photons $\left.\mathrm{m}^{-2} \mathrm{~s}^{-1}\right)$ supports a steady-state surface layer phytoplankton biomass in systems with time-constant mixing (scenarios $M_{C}$ ) that is predominantly limited by the nutrients available from the diffusive flux of nutrients. In systems with seasonal mixing (scenarios $M_{S}$ ), the maximum biomass during the spring bloom exceeds the steady-state biomass in the corresponding systems without winter mixing, because phytoplankton production additionally can utilise the annually renewed nutrient pool. This resource pool supplies sufficient nutrients that biomass production and the rate of pool exploitation is controlled by light limitation. An increase of incident light intensity therefore increases specific production whereas loss rates remain unaffected. As a consequence, the net production rate of biomass is larger and the exploitation of the nutrient pool is faster the larger the intensity of the incident light, $I_{o}$. Because the cumulative losses of phytoplankton through sedimentation increase with time, the maximum biomass produced from the same nutrient pool is larger the faster the nutrient pool is exploited. This explains why in the simulations with seasonal mixing the annual maximum water column production and water column abundance, $B_{\max }$, increase significantly with increasing incident light intensity, whereas steady-state water column production and steady-state water column abundance, $B_{\text {stead, in the simulations with time-constant }}$ mixing are rather insensitive to light intensity in case of a the shallow surface-mixed layer $\left(S_{d}=5 \mathrm{~m}\right)$.

At large surface-mixed layer depths $S_{d}$, water column production by the phytoplankton mixed vertically over $S_{d}$ is predominantly limited by light intensity. Therefore, the supply of nutrients by an annually renewed resource pool in seasonally-mixed systems or higher nutrient concentrations in systems of generally higher trophic state, $R_{\text {troply }}$, have no significant affect on the annual maximum water column phytoplankton abundance (Figs. $3 \mathrm{e}, \mathrm{f}$ and $4 \mathrm{j}$ ). Consequently, at a surface-mixed layer depth of $S_{d}=20 \mathrm{~m}$, the maximum water column abundance in seasonally-mixed systems, $B_{\max }$, and the steady state water column abundance in corresponding systems without winter mixing, $B_{\text {stead }}$, agree closely and are not very sensitive to changes in trophic state (Fig. 4j), but increase significantly and at a similar rate with increasing intensity of the incident light (Fig. 4h).

Our model did not consider seasonal changes in incident light intensity, although this is known to affect phytoplankton dynamics (e.g. Litchman and Klausmeier 2001). However, in the standard model $M_{S}$ considering a $50-\mathrm{m}$ deep water column with a mixed surface layer depth of $S_{d}=5 \mathrm{~m}$, seasonal mixing resulted in a seasonal change of water column biomass that was four times larger than the change in steady-state biomass in model $M_{C}$ resulting from an increase in incident light intensity from 100 to $600 \mu \mathrm{mol}$ photons $\mathrm{m}^{-2} \mathrm{~s}^{-1}$. Note further that the main seasonal change in light intensity typically occurs over the winter/early spring period when vertical mixing is intense and light limitation of water column production in deep systems is dominated by the downward transport of phytoplankton within the vertical light gradient. Seasonal changes in incident light intensity thus probably have a minor effect on phytoplankton abundance in deep seasonally-mixed lakes with shallow surface layers (see also Peeters et al. 2007a), but may be more important in aquatic systems that are e.g. shallow, eutrophic, or located at high latitudes.

\section{Persistence}

Seasonal mixing also affects the persistence ranges of phytoplankton by decreasing the annual average of light availability for phytoplankton and by increasing the nutrient supply via replenishment of the nutrient pool during winter mixing. In systems with low diffusivities during stratified conditions, seasonal mixing can thus support the development of higher abundances of phytoplankton (Fig. 6a, b) or even prevent the extinction of phytoplankton (Fig. $3 M_{S, R d 0}$ ) compared to systems without winter mixing. In contrast, in systems with low light intensities and large surface-mixed layer depths seasonal mixing may cause extinction of phytoplankton as light limitation is more important than nutrient limitation (Fig. 4b). Introducing an intermediate layer of low mixing during stratified conditions reduces vertical transport of phytoplankton from the euphotic zone to deeper water layers and thus reduces the overall water column effects of light limitation. Hence, the presence of an intermediate layer 
supports persistence of phytoplankton in systems, in which the mixing intensity without the intermediate layer would cause such a rapid export of phytoplankton from the euphotic zone that the effects of light limitation lead to extinction of the phytoplankton population (Fig. 6a-d). However, because the intermediate layer also reduces the flux of nutrients from the nutrient-rich deep water to the surface layer, it not only lowers the effects of light limitation but also increases nutrient limitation in the euphotic zone. Hence, low diffusivities in the intermediate layer may result in a reduction of phytoplankton a bundances (e.g. Figs. 3 e $M_{S, R d 0}$ and $6 \mathrm{c}$ ) or even extinction of phytoplankton (Fig. 3f $M_{C \text {, Rdo }}$ ). The consequences of an intermediate layer of low mixing for phytoplankton abundance and persistence depends on the mixed-layer depth, the mixing intensity in the surface layer and on the consideration of seasonal mixing.

\section{Phenology of phytoplankton blooms}

The sensitivity of the timing of the annual maximum in water column phytoplankton abundance to light intensity, trophic state, mixed layer depth and mixing duration supports the important role of pool exploitation for phytoplankton bloom development. An increase in light intensity increases specific production and thus leads to a faster exploitation of the resource pool and hence to an earlier bloom development. In contrast, nutrient enrichment delays the phytoplankton peak as it increases the nutrient pool and thus the time required to exploit the nutrient pool. Nutrient enrichment also increases specific production but this has only a small effect since nutrient limitation is already low after winter mixing (see Fig. 2). With increasing mixedlayer depth the annual phytoplankton peak is delayed, because the nutrient pool increases with mixed-layer depth and the average specific production within the surface layer decreases with mixed layer depth due to increased light limitation of the phytoplankton.

The model results on the phenology of phytoplankton are consistent with in situ observations in different temperate lakes and mesocosm studies. For example, the spring bloom can be delayed by a decrease in light intensity (Sommer and Lengfellner 2008), by an increase in mixing depth (Berger et al. 2007) and by a late termination of winter mixing (Peeters et al. 2007a; Thackeray et al. 2008). However, in contrast to the model predictions Thackeray et al. (2008) observed an advance of the timing of the spring bloom of the diatom Asterionella formosa with increasing nutrient concentration in Lake Windermere. This discrepancy might be because other factors related to trophic state (e.g., abundances of competitors, e.g. of earlier blooming Cyclotella, or of herbivores) have interfered with the predicted effect of nutrients, or because phosphorus concentrations in Windermere were below those considered in our study. Our simulations also indicate that the sensitivity of phytoplankton phenology to changes in nutrient enrichment and light intensity depends on the mixed layer depth. In systems with small mixed-layer depth, the influence of incident light intensity and trophic state on phenology is of minor importance compared to that of the timing of onset of stratification. This conclusion is consistent with the findings from Lake Constance (Peeters et al. 2007a), where temperature stratification during the spring season reaches almost to the lake surface.

The duration of winter-mixing affects bloom timing by changing the onset of stratification, but also by changing overwintering biomasses, i.e. the annual minimum water column biomass. The sensitivity of timing of the phytoplankton bloom to overwintering biomass increases with mixed-layer depth (Fig. 5d) suggesting that overwintering biomass may be important especially in deeper lakes and marine systems. Consequently, for these systems, predictions from the analyses of transient dynamics (e.g. Jäger et al. 2008) which rely on the assumption that results are insensitive to initial conditions, should be carefully evaluated. In the seasonally resolved model employed here, overwintering biomass evolves as part of the seasonal development of phytoplankton and follows mechanistically from the seasonal change in abiotic conditions. The model predicts a slight delay of bloom timing with decreasing overwintering biomass (Fig. 5) as was observed for example for two diatoms in Lake Windermere (Thackeray et al. 2008). Several other field and experimental studies also suggest that winter conditions can be important for biomasses and processes as the season progresses (Sommer and Lewandowska 2011; Anneville et al. 2004; Wiltshire et al. 2008).

\section{Conclusions}

This work has shown that models with and without seasonal mixing make different predictions regarding phytoplankton biomass, phytoplankton production and their sensitivity to environmental conditions. In seasonally-mixed systems, the vertical distribution of mixing intensity during stratified conditions, especially the depth of the transition from high mixing in the surface layer to low mixing in the thermocline, determines the importance of the exploitation of the nutrient pool in relation to the diffusive nutrient flux, and also in relation to light limitation resulting from vertical transport of phytoplankton. Hence, the combination of seasonally and spatially varying mixing intensities has a major effect on the relative importance of abiotic conditions (e.g. vertical transport, incident light and trophic state) versus biotic properties (e.g. physiological parameters relevant for the specific growth rates and sedimentation velocity) for the growth of light- and nutrient-limited phytoplankton.

This suggests that seasonal mixing may differentially affect the performance of phytoplankton with different physiological traits and thus may have an influence on the 
competitive abilities of phytoplankton species in vertical Water columns. It has already been shown that temporal variations in mixing intensity affect competition between sinking algae and buoyant cyanobacteria (Huisman et al. 2004; Jöhnk et al. 2008). Further, it has been demonstrated, that periodic short-term mixing of a part of the vertical water column can alter the competitive advantage between small and large sinking algae with different storage and nutrient utilisation capabilities (Kerimoglu et al. 2012). However, most of the theoretical studies that have investigated phytoplankton in vertically resolved systems have assumed time-constant mixing (e.g. Yoshiyama et al. 2009; Jäger et al. 2010; Mellard et al. 2011; Ryabov and Blasius 2011). Whether the conclusions from such investigations neglecting seasonal mixing are valid also in natural systems that are mixed seasonally may be assessed by studies investigating the implications of seasonal mixing on competition in phytoplankton.

Understanding of phytoplankton dynamics has been strongly improved by considering phytoplankton, light and nutrients in vertically resolved models some of which also considering a vertical distribution of mixing intensities (e.g. Huisman et al. 2006; Ryabov et al. 2010; Jäger et al. 2010; Mellard et al. 2011). Our study suggests that an important next step is to fully incorporate also the seasonal dynamics of mixing patterns in theoretical models. This is especially of importance as climate warming is expected to alter not only the vertical patterns, but also the seasonal patterns of mixing in lakes (Peeters et al. 2007b; Straile et al. 2010).

Acknowledgeents We thank S. Diehl and an unknown reviewer for comments on the manuscript. This research was conducted within the "research center for organismic interactions in aquatic ecosystems under changing conditions" at the University of Konstanz, and was financially supported by the Deutsche Forschungsgemeinschaft (within the priority program 1162 "AQUASHIFT", Pe 701/2 3).

\section{References}

Anneville O, Soussi S, Gammeter S, Straile D (2004) Seasonal and inter-annual scales of variability in phytoplankton assemblages: comparison of phytoplankton dynamics in three peri-alpine lakes over a period of 28 years. Freshwater Biol 49:98-115

Berger SA, Diehl S, Stibor HS, Trommer G, Ruhenstroth M, Wild A, Weigert $A$, Jäger $C G$, Striebel $M$ (2007) Water temperature and mixing depth affect timing and magnitude of events during spring succession of the plankton. Oecologia 150:643-654

Boehrer B, Schultze M (2008) Stratification of lakes. Rev Geophys 46: RG2005. doi:10.1029/2006RG000210

Diehl S (2002) Phytoplankton, light, and nutrients in a gradient of mixing depths: theory. Ecology 83:386-398

Dieh1 S, Berger S, Ptacnik R, Wild A (2002) Phytoplankton, light, and nutrients in a gradient of mixing depths: field experiments. Ecology $83: 399-411$

Diehl S, Berger S, Wohrl R (2005) Flexible nutrient stoichiometry mediates environmental influences, on phytoplankton and its resources. Ecology 86:2931-2945
Edwards M, Richardson AJ (2004) Impact of climate change on marine pelagic phenology and trophic mismatch. Nature 430:881-884

Etemad-Shahidi A, Imberger $I$ (2006) Diapycnal mixing in the thermocline of lakes: estimations by different methods. Environ Fluid Mech 6:227-240

Falkowski PG (1994) The role of phytoplankton photosynthesis in global biogeochemical cycles. Photosynth Res 39:235-258

Fischer HB, List EJ, Koh RCY, Imberger J, Brooks NH (1979) Mixing in inland and coastal waters. Academic Press, New York, p 483

Hastings A (2004) Transients: the key to long-term ecological understanding? Trends Ecol Evol 19:39 45

Huisman J, Sommeijer B (2002) Maximal sustainable sinking velocity of phytoplankton. Mar Ecol-Prog Ser 244:39-48

Huisman J, Weissing FJ (1995) Competition for nutrients and light in a mixed water columm: a theoretical analysis. Am Nat 146:536-564

Huisman J, van Oostveen P, Weissing FJ (1999) Critical depth and critical turbulence: two different mechanisms for the development of phytoplankton blooms. Limnol Oceanogr 44:1781-1787

Huisman J, Arrayas M, Ebert U, Sommeijer B (2002) How do sinking phytoplankton species manage to persist? Am Nat 159:245-254

Huisman J, Sharples J, Stroom J, Visser PM, Kardinaal WEA, Verspagen $\mathrm{JMH}$, Sommeijer B (2004) Changes in turbulent mixing shift competition for light between phytoplankton species. Ecology $85: 2960-2970$

Huisman J, Thi NNP, Karl DM, Sommeijer B (2006) Reduced mixing generates oscillations and chaos in the oceanic deep chlorophyll maximum. Nature 439:322 -325

Huppert A, Blasius B, Stone L (2002) A model of phytoplankton blooms. Am Nat 159:156-171

Huppert A, Blasius B, Olinky R, Stone L (2005) A model of seasonal phytoplankton blooms. J Theor Biol 236:276-290

Hutchinson GE (1957) A treatise on limnology. I. Geography, physics and chemistry. Wiley, New York, p 1015

Imboden DM, Wüest A (1995) Mixing mechanisms in lakes. In: Lerman A, Imboden DM, Gat J (eds) Physics and chemistry of lakes. Springer, Heidleberg, pp 83-138

Jäger CG, Diehl S, Matauschek C, Klausmeier CA, Stibor H (2008) Transient dynamics of pelagic producer grazer systems in a gradient of nutrients and mixing depths. Ecology 89:1272-1286

Jäger CG, Diehl S, Emans M (2010) Physical determinants of phytoplankton production, algal stoichiometry, and vertical nutrient fluxes. Am Nat 175:E91-E104

Jöhnk KD, Huisman J, Sharples J, Sommeijer B, Visser PM, Stroom JM (2008) Summer heatwaves promote blooms of harmful cyanobacteria. Glob Change Biol 14:495-512

Kerimoglu O, Straile D, Peeters F (2012) Role of phytoplankton cell size on the competition for nutrients and light in incompletely mixed systems. J Theor Biol 300:330-343

Kiorboe T, Lundsgaard C, Olesen M, Hansen JLS (1994) Aggregation and sedimentation processes during a spring phytoplankton bloom: a field experiment to test coagulation theory. J Mar Res 52:297-323

Landsberg $\mathrm{JH}$ (2002) The effects of harmful algal blooms on aquatic organisms. Rev Fish Sci 10:113-390

Lehr JH, Lehr JK (2000) Standard handbook of environmental science, health, and technology. McGraw-Hill, New York, p 1600

Li YH (1973) Vertical eddy diffusion coefficient in lake Zurich. Schweiz Z Hydrol 35:1-7

Litchman $E_{*}$ Klausmeier CA (2001) Competition of phytoplankton under fluctuating light. Am Nat 157:170-187

Mellard JP, Yoshiyama K, Litchman E, Klausmeier CA (2011) The vertical distribution of phytoplankton in stratified water columns. J Theor Biol 269:16-30

O'Brien KR, Ivey GN, Hamilton DP, Waite AM, Visser PM (2003) Simple mixing criteria for the growth of negatively buoyant phytoplankton. Limnol Oceanogr 48:1326-1337 
Peeters F, Straile D, Lorke A, Ollinger D (2007a) Turbulent mixing and phytoplankton spring bloom development in a deep lake. Limnol Oceanogr 52:286-298

Peeters F, Straile D, Lorke A, Livingstone DM (2007b) Earlier onset of the spring phytoplankton bloom in lakes of the temperate zone in a warmer climate. Glob Change Biol 13:1898-1909

Ryabov AB, Blasius B (2011) A graphical theory of competition on spatial resource gradients. Ecol Lett 14:220-228

Ryabov AB, Rudolf L, Blasius B (2010) Vertical distribution and composition of phytoplankton under the influence of an upper mixed layer. $J$ Theor Biol 263:120-133

Schalau K. Rinke K, Straile D, Peeters F (2008) Temperature is the key factor explaining interannual variability of Daphnia development in spring: a modelling study. Oecologia 157:531-543

Schwarzenbach RP, Gschwend PM, Imboden DM (2003) Environmental organic chemistry, 2nd edn. Wiley, New York

Seebens H, Einsle U, Straile D (2009) Copepod life cycle adaptations and success in response to phytoplankton spring bloom phenology. Glob Change Biol 15:1394-1404

Sharples J, Ross ON, Scott BE, Greenstreet SPR, Fraser H (2006) Interannual variability in the timing of stratification and the spring bloom in the North-western North Sea. Cont Shelf Res 26:733-751

Sommer U (1985) Comparison between steady-state and nonsteady state competition: experiments with natural phytoplankton. Limnol Oceanogr $30: 335-346$

Sommer U, Lengfellner $\mathrm{K}$ (2008) Climate change and the timing, magnitude, and composition of the phytoplankton spring bloom. Glob Change Biol 14:1199-1208
Sommer U, Lewandowska A (2011) Climate change and the phytoplankton spring bloom: warming and overwintering zooplankton have similar effects on phytoplankton. Glob Change Biol 17:154-162

Sommer U, Gliwicz ZM, Lampert W, Duncan A (1986) The PEGmodel of seasonal succession of planktonic events in fresh waters. Arch Hydrobiol 106:433-471

Straile D, Kerimoglu O, Peeters F, Jochimsen MC, Kümmerlin R, Rinke K, Rothhaupt KO (2010) Effects of a half a millennium winter on a deep lake-a shape of things to come? Glob Change Biol 16:2844-2856

Thackeray SJ, Jones ID, Maberly SC (2008) Long-term change in the phenology of spring phytoplankton: species-specific responses to nutrient enrichment and climatic change. $J$ Ecol 96:523-535

Wiltshire KH, Malzahn AM, Wirtz K, Greve W, Janisch S, Mangelsdorf P, Manly BFJ, Boersma M (2008) Resilience of North Sea phytoplankton spring bloom dynamics: an analysis of long-term data at Helgoland roads. Limnol Oceanogr 53:1294-1302

Winder M, Schindler DE (2004) Climate change uncouples trophic interactions in an aquatic ecosystem. Ecology 85:2100-2106

Yoshiyama K, Nakajima $H$ (2002) Catastrophic transition in vertical distributions of phytoplankton: alternative equilibria in a water column. J Theor Biol 216:397-408

Yoshiyama K, Mellard JP, Litchman E, Klausmeier CA (2009) Phytoplankton competition for nutrients and light in a stratified water column. Am Nat 174:190-203 


\section{Electronic supplement to}

Title: Implications of seasonal mixing for phytoplankton production and bloom development Journal: Theoretical Ecology

Authors: F. Peeters, O. Kerimoglu, D. Straile

Affiliation of the authors: Limnological Institute, University of Konstanz, Mainaustrasse 252, D-78464 Konstanz, Germany

Corresponding author: Frank Peeters

e-mail: frank.peeters@uni-konstanz.de

tel.: 49-7531-88-3459

fax.:49-7531-88-3533

This electronic supplement consists of three parts:

(1) A sensitivity analysis of the phytoplankton population development with respect to surface layer thickness $S_{d}$ and diffusivity within the surface layer $d_{S}$;

(2) An analysis examining the time periods of agreement and a quantification of the deviation between water column production in $\mathrm{M}_{\mathrm{C}}$ and in $\mathrm{M}_{\mathrm{S}}$;

(3) A sensitivity analysis of the development of phytoplankton biomass in a model assuming fixed stoichiometry considering the same parameter ranges for light intensity, trophic state and duration of winter mixing as in the main manuscript.

\section{Sensitivity analysis with respect to surface layer thickness $S_{d}$ and diffusivity within the surface layer $d_{S}$}

$B_{\max }$ not only depends on the thickness of the surface layer but also on the diffusivity within this layer. If $S_{d} \leq 10 \mathrm{~m} B_{\max }$ is independent of $d_{S}$ as long as $d_{S} \geq 10 \mathrm{~m}^{2} \mathrm{~d}^{-1}$, whereas for $S_{d}$ $>10 \mathrm{~m} B_{\max }$ is maximal at $d_{S}$ of about $10 \mathrm{~m}^{2} \mathrm{~d}^{-1}$ and is smaller for larger and smaller $d_{S}$ (Fig. O1a). If the depth of the surface layer is less than $20 \mathrm{~m}, S_{d} \leq 20 \mathrm{~m}$, a seasonal phytoplankton peak develops in all our simulations substantially before the onset of winter mixing and independent of the value of $d_{S}$ (Fig. O1b, c). However, if $S_{d}=25 \mathrm{~m}$ and mixing intensity in the surface layer is high, light limitation can become sufficiently large that the increase in phytoplankton biomass during stratified conditions is slow and is interrupted by the winter mixing such that the maximum annual biomass is reached immediately before winter mixing (Fig Olb, d). Note, that if $d_{S}<50 \mathrm{~m}^{2} \mathrm{~d}^{-1}$ also in the case of $S_{d}=25 \mathrm{~m}$ is the phytoplankton growth rate sufficiently fast to cause self-exploitation of nutrients and leads to an annual 
phytoplankton peak before the onset of winter mixing (Fig Olb, d). In this case $B_{\max }$ is higher than in the simulations with higher $d_{S}$ in which the maximum phytoplankton biomass is on ly reached when winter mixing sets in. Fig. Ol thus demonstrates that the importance of the exploitation of the nutrient pool by the growing phytoplankton population and the resulting effect of nutrient limitation on $B_{\max }$ depends on the growth rate of phytoplankton within the surface layer and thus on both $S_{d}$ and $d_{S}$.
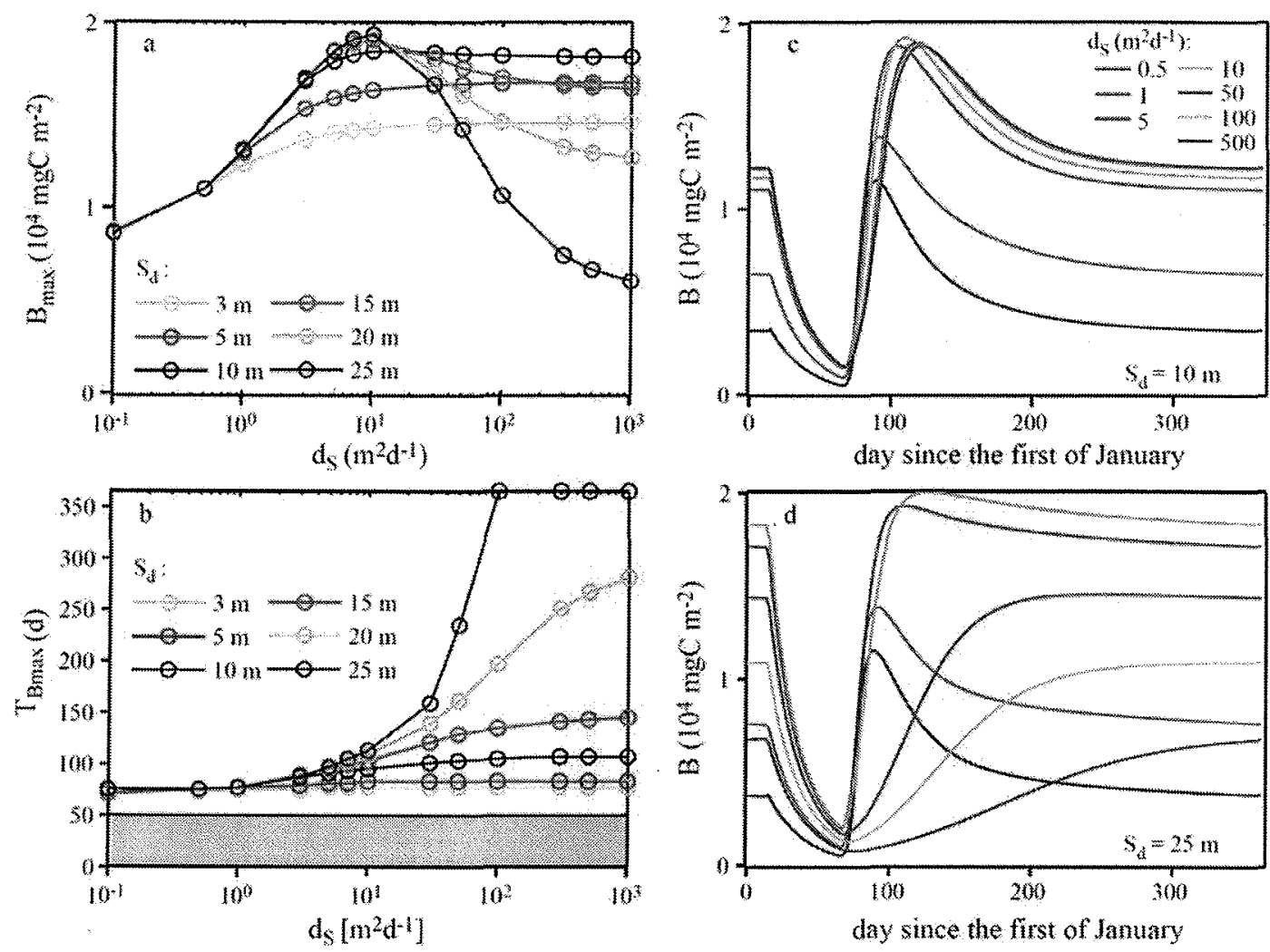

Fig. O1: Sensitivity analysis with respect to surface layer thickness $S_{d}$ and diffusivity within the surface layer $d_{S}$. The dependence of $B_{\max }$ and of the timing of the annual phytoplankton peak on surface layer diffusivity $d_{S}$ and thickness $S_{d}$ (colours) are illustrated in (a) and (b), respectively, where the symbols indicate the $S_{d}$ for which simulations were performed. The dependence of the seasonal course of phytoplankton abundance $B$ on diffusivity $d_{S}$ (coloured lines in c and d) is exemplified for $S_{d}=10 \mathrm{~m}$ and $S_{d}=25 \mathrm{~m}$ in (c) and (d), respectively. All simulations consider a $50 \mathrm{~m}$ deep water column, a $5 \mathrm{~m}$ thick intermediate layer with $d_{l}=0.5$ $\mathrm{m}^{2} \mathrm{~d}^{-1}$ and a deep water layer with $d_{D}=5 \mathrm{~m}^{2} \mathrm{~d}^{-1}$. During each year seasonal winter mixing prevailed between day 15 and day 65 with $d_{t m i x}=1000 \mathrm{~m}^{2} \mathrm{~d}^{-1}$. 


\section{Time periods of agreement and quantification of the deviation between water column}

production in $\mathbf{M}_{\mathrm{C}}$ and in $\mathrm{M}_{\mathrm{S}}$

Phytoplankton production, abundances and nutrient concentrations at steady state in models assuming time-constant diffusivities differ from the values of the corresponding variables in models that consider seasonal mixing. However, the deviations of $P, B$ and $R_{d m e a n}$ between models with and without winter mixing decrease towards the end of the stratified period. The fraction of the year during which $P$ at steady state in $\mathrm{M}_{\mathrm{C}}$ deviates by less than $5 \%$ and $10 \%\left(F_{P, 5 \%}, F_{P, 1} \%\right)$, respectively, from $B$ in seasonally mixed models is depicted in Fig. O2. In systems with $S_{d}=5 \mathrm{~m}, F_{P, 5 \%}$ is typically around $50 \%$ indicating that during about half of the year $P$ in $M_{C}$ deviates by more than $5 \%$ from $P$ in $M_{S}$. During about $40 \%$ of the season $P$ in $\mathrm{M}_{\mathrm{C}}$ differs from $\mathrm{P}$ in $\mathrm{M}_{\mathrm{S}}$ by more than $10 \%$. In systems with a large surface mixed layer depth $\left(S_{d}=20 \mathrm{~m}\right)$ and especially if $R_{\text {troph }}$ is small, the agreement at the $5 \%$ level between $P$ in $\mathrm{M}_{\mathrm{C}}$ and $P$ in $\mathrm{M}_{\mathrm{S}}$ is restricted to $20 \%$ of the season. Note that a $5 \%$ higher production accumulates to a large difference in produced biomass within a few days.

The results for water column biomass $B$ and $R_{\text {dmean }}$ are similar to those of water column production. The time period of agreement between $B$ in $\mathrm{M}_{\mathrm{C}}$ and $B$ in $\mathrm{M}_{\mathrm{S}}$ is even slightly smaller than for water column production.

The deviation between water column production in $M_{S}$ and at steady state in $M_{C}$ is quantified by calculating the root-mean square deviation between $P$ in $\mathrm{M}_{\mathrm{S}}$ and $P$ at steady state in $M_{C}$ considering the simulated water column production in $M_{S}$ over a full year time period. The root-mean square deviation is divided by $P$ at steady in $\mathrm{M}_{\mathrm{C}}$ providing the rmsdeviation between $P$ in $\mathrm{M}_{\mathrm{S}}$ and $P$ at steady state in $\mathrm{M}_{\mathrm{C}}$ depicted in Fig. O3. In most simulations the rms-deviation is larger than $40 \%$ indicating that water column production at steady state in $\mathrm{M}_{\mathrm{C}}$ substantially differs from water column production in $\mathrm{M}_{\mathrm{S}}$ suggesting that $P$ at steady state in $\mathrm{M}_{\mathrm{C}}$ cannot serve as a proxy for phytoplankton production in seasonally mixed systems. 

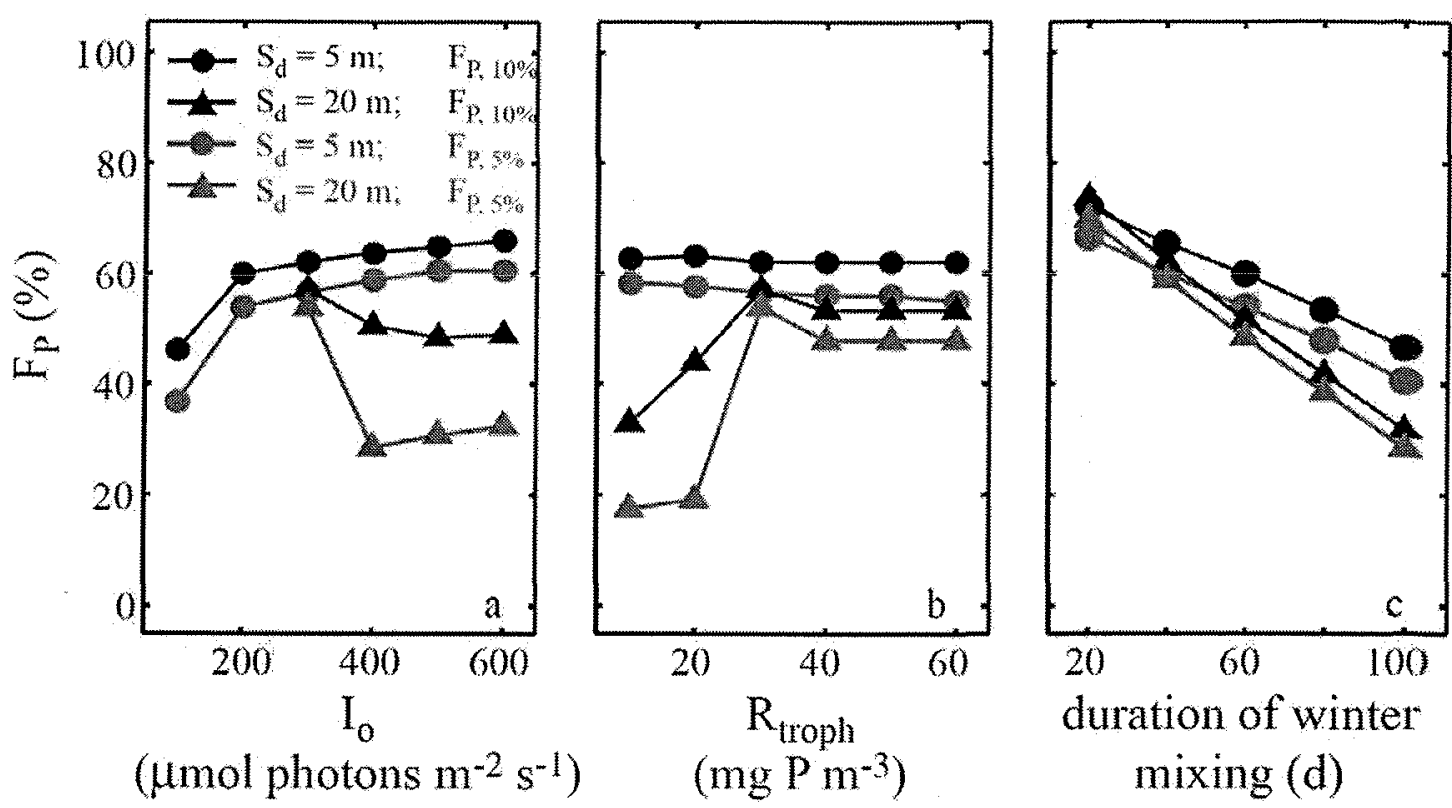

Fig. 02: Fraction of the season $F_{P}$, during which $P$ at steady state in $\mathrm{M}_{\mathrm{C}}$ differs by less than $5 \%$ and $10 \%$, respectively, from $P$ simulated with the corresponding seasonally mixed model. (a), (b) and (c) demonstrate the sensitivity of $F_{P}$ to changes in light intensity, nutrient enrichment and the duration of winter mixing. Furthermore, the symbols depict simulations with shallow (circles: $S_{d}=5 \mathrm{~m}$ ) and deep (triangles: $S_{d}=20 \mathrm{~m}$ ) surface mixed layers. Results for an agreement level of $5 \%$ and $10 \%$ are shown in red and black, respectively. $F_{p}$ are not shown for $S_{d}=20 \mathrm{~m}$ and $\mathrm{I}_{\mathrm{o}} \leq 200 \mu \mathrm{mol}$ photons $\mathrm{m}^{-2} \mathrm{~s}^{-1}$ because under these conditions phytoplankton and thus also water column production in $\mathrm{M}_{\mathrm{S}}$ become very low such that percent deviations from these low values may be misleading. 

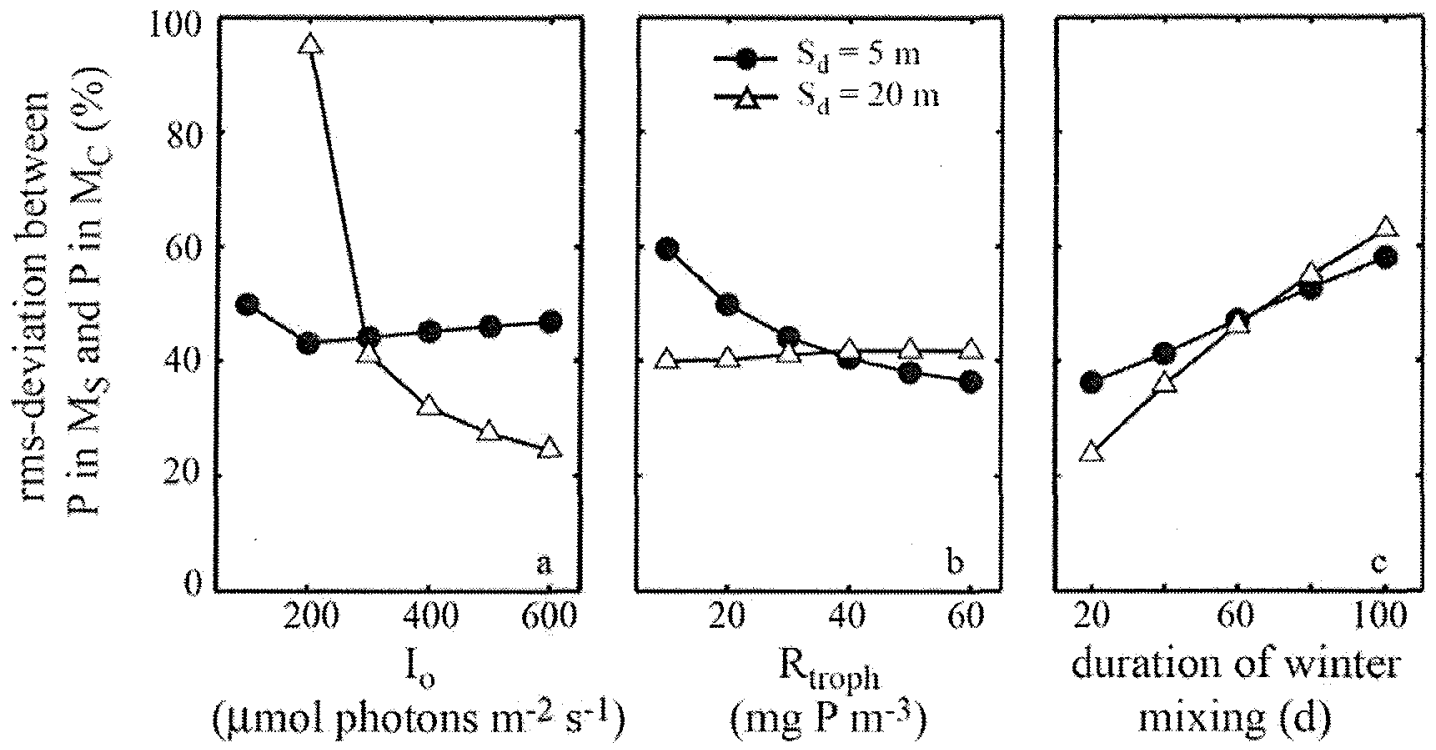

Fig. O3: Root-mean-square deviation between $P$ in $M_{S}$ and $P$ at steady state in $M_{C}$ expressed as percentage of $P$ at steady state in $\mathrm{M}_{\mathrm{C}}$. (a), (b) and (c) demonstrate the sensitivity of the rmsdeviation to changes in light intensity, nutrient enrichment and the duration of winter mixing. Furthermore, the symbols depict simulations with shallow (circles: $S_{d}=5 \mathrm{~m}$ ) and deep (triangles: $S_{d}=20 \mathrm{~m}$ ) surface mixed layers. 


\section{Sensitivity analysis of the development of phytoplankton biomass in a model assuming}

\section{fixed stoichiometry}

The seasonal development of phytoplankton abundance obtained from the simulations with the vertically resolved variable internal stores phytoplankton model shows only a single phytoplankton peak without further oscillations. In this section we demonstrate that the rather smooth seasonal development of phytoplankton biomass is not a consequence of stabilizing effects of the variable internal nutrient storage but is similarly smooth if phytoplankton development is simulated with a model assuming fixed stoichiometry. First we briefly describe the model with fixed stoichiometry and then present model results for the same scenarios as in Fig. 4 of the main part of the paper.

The model with fixed stoichiometry as well as the parameterization of this model was taken from Jäger et al. (2010). It is a simplification of the stoichiometric flexible internal stores model of the main manuscript (eq. 1). The model assumes a fixed cell quota, which makes the dynamic simulation of bound particulate nutrients as separate state variable unnecessary. The concentration of bound particulate nutrients can be calculated directly from the algae concentration using the fixed cell quota. Hence the model equations reduce to (from Jäger et al. 2010):

$$
\begin{aligned}
& \frac{\partial A}{\partial t}=\quad p_{s p e c}\left(I, R_{d}\right) \cdot A \quad-l_{b g} \cdot A-v \cdot \frac{\partial A}{\partial z} \quad+\frac{\partial}{\partial z}\left(d \cdot \frac{\partial A}{\partial z}\right) \\
& \frac{\partial R_{d}}{\partial t}=-p_{s p e c}\left(I, R_{d}\right) \cdot A \cdot q_{f i x}+l_{b g} \cdot R_{b} \quad+\frac{\partial}{\partial z}\left(d \cdot \frac{\partial R_{d}}{\partial z}\right) \\
& \frac{\partial R_{s}}{\partial t}=v \cdot A\left(z_{\max }\right) \cdot q_{f i x}-r \cdot R_{s} \\
& p_{\text {spec }}\left(I, R_{d}\right)=\mu_{\text {max }}^{\prime} \frac{R_{d}}{m+R_{d}} \cdot \frac{I(z)}{h+I(z)} \\
& I(z)=I_{0} \exp \left(-\int_{0}^{z}\left(k \cdot A+k_{b g}\right) d z\right)
\end{aligned}
$$

All parameters are taken from Jäger et al (2010). In the models with flexible and fixed stoichiometry corresponding parameters have the same value (see table 1 of the main manuscript). In the model with fixed stoichiometry the cell-quotas are assumed to agree with Redfield stoichiometry, $q_{f i x}=0.0244 \mathrm{mgP} / \mathrm{mgC}$, and the maximum production rate is $\mu_{\max }^{\prime}=\mu_{\max }\left(1-q_{\min } / q_{\max }\right)$. The same initial conditions were employed in the models with flexible and with fix stoichiometry, also taken from Jäger et al. (2010). 
As in the simulations with the model with flexible stoichiometry presented in Fig.4 of the main manuscript, we assumed a $50 \mathrm{~m}$ deep water column that is seasonally mixed. Rigorous winter mixing throughout the water column prevails for 50 days (except in the scenarios considering different durations of winter mixing) beginning on day 15 of each year of 365 days $\left(d_{\text {tmix }}=1000 \mathrm{~m}^{2} \mathrm{~d}^{-1}\right.$ at all depth). Winter mixing is followed by a stratified period characterized by a surface mixed layer of thickness $S_{d}\left(d_{s}=1000 \mathrm{~m}^{2} \mathrm{~d}^{-1}\right)$, a $5 \mathrm{~m}$ thick metalimnion with low mixing intensity $\left(d_{l}=0.5 \mathrm{~m}^{2} \mathrm{~d}^{-1}\right)$ and a weakly mixed hypolimnion $\left(d_{D}\right.$ $=0.5 \mathrm{~m}^{2} \mathrm{~d}^{-1}$ ).

Fig. O4 presents results from simulations using the vertically resolved phytoplankton model with seasonal mixing and fixed stoichiometry assuming surface mixed layer depths of $S_{d}=5 \mathrm{~m}$ and of $S_{d}=20 \mathrm{~m}$, different intensities of incident light, trophic states and durations of winter mixing. The dynamic properties of the seasonal development of phytoplankton biomass, i.e. the smoothness of the transitions and the absence of oscillations except for a single seasonal phytoplankton peak, are rather similar to those obtained from the model considering internally stored nutrients with flexible stoichiometry (Fig. 4 of the main manuscript). This indicates that the smoothness of the seasonal transitions with a single seasonal peak is not a consequence of the stabilizing effect of internally stored nutrients but a typical feature of seasonally forced phytoplankton in vertically resolved models, independent of whether stoichiometry is flexible or not. 

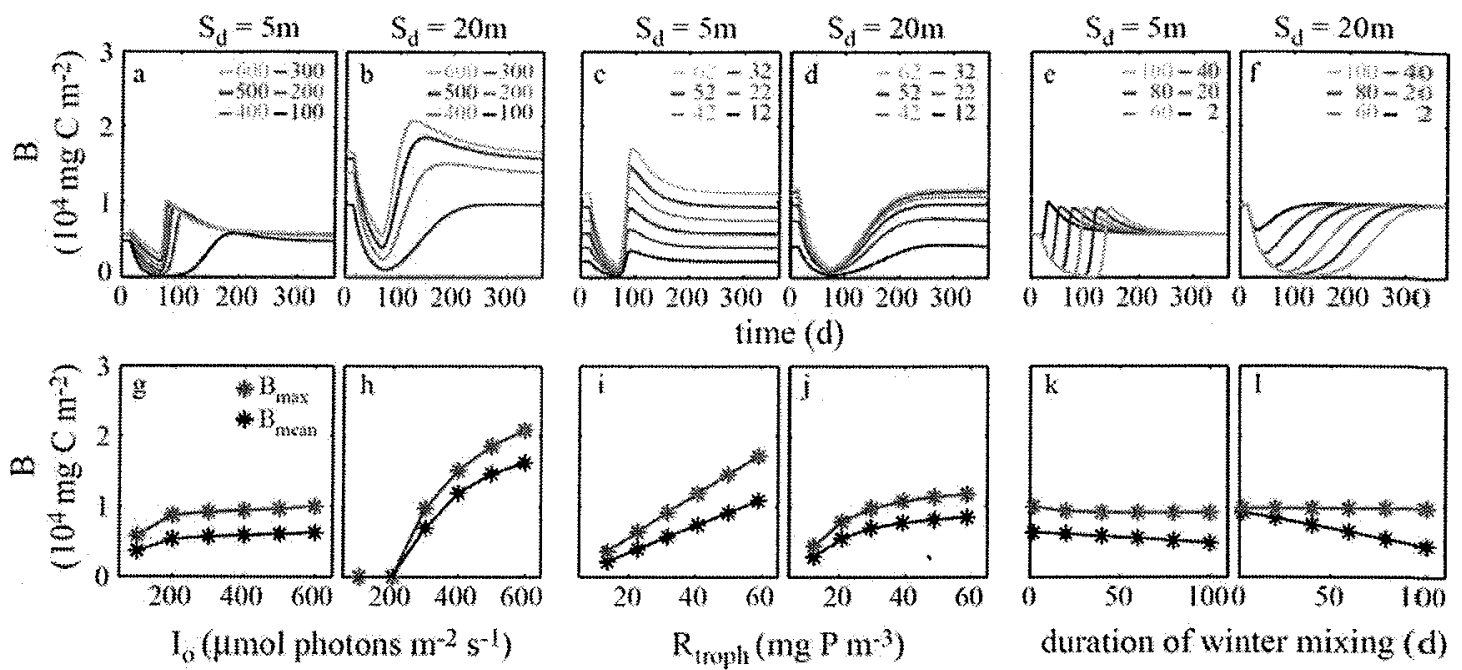

Fig. O4: Sensitivity of water column phytoplankton biomass to incident light (a, b, g, h), trophic state $(c, d, i, j)$ and duration of winter mixing (e, $f, k, 1)$ as in Fig. 4, but with a model assuming fixed stoichiometry. Panels a-f show the seasonal course of phytoplankton biomass $B$ for different abiotic conditions, whereas panels g-1 depict the annual maximum of $B, B_{\max }$, and the annual mean of $B, B_{\text {mean }}$, of simulations with seasonal mixing. Except for the parameter of the sensitivity analysis of the particular panel $I_{o}=300 \mu \mathrm{mol}$ photons $\mathrm{m}^{-2} \mathrm{~s}^{-1}$, $R_{\text {troph }}=32.2 \mathrm{mg} \mathrm{P} \mathrm{m}^{-3}$ and the duration of winter mixing was $t_{m i x}=50 \mathrm{~d}$. Note, that $S_{d}=5 \mathrm{~m}$ in panels a, c, e, g, i, k, whereas $S_{d}=20 \mathrm{~m}$ in panels b, d, f, h, j, l. For all the tested parameter combinations, the model produced a rather smooth seasonal phytoplankton development characterized by a single seasonal phytoplankton peak without further oscillations as in the case of the model with flexible stoichiometry. 